\title{
Uncertainty in Climate Change Modeling: Can Global Sensitivity Analysis Be of Help?
}

\author{
Barry Anderson, ${ }^{1}$ Emanuele Borgonovo, ${ }^{2, *}$ Marzio Galeotti, ${ }^{1,3}$ and Roberto Roson ${ }^{1,4}$
}

\begin{abstract}
Integrated assessment models offer a crucial support to decisionmakers in climate policy making. For a full understanding and corroboration of model results, analysts ought to identify the exogenous variables that influence the model results the most (key drivers), appraise the relevance of interactions, and the direction of change associated with the simultaneous variation of uncertain variables. We show that such information can be directly extracted from the data set produced by Monte Carlo simulations. Our discussion is guided by the application to the well-known DICE model of William Nordhaus. The proposed methodology allows analysts to draw robust insights into the dependence of future atmospheric temperature, global emissions, and carbon costs and taxes on the model's exogenous variables.
\end{abstract}

KEY WORDS: Climate change; global sensitivity analysis; integrated assessment modeling; risk analysis.

\section{INTRODUCTION}

Climate change is a very complex phenomenon, which affects our society in multiple ways with consequences that reach far into the future. Uncertainty permeates the economic evaluation of damages and of mitigation policies. ${ }^{(1-4)}$ As underlined in the literature, "increasingly climate scientists are adopting the tools and techniques of risk analysis in their efforts to characterize future climate uncertainties." (5, p. 1387) Aven ${ }^{(6-8)}$ comprehensively discusses the treatment of uncertainties in risk analysis. In the editorial of the recent Risk Analysis special issue on climate change perception, Pidgeon notes that "the need to develop robust tools to help decision-makers remain as pressing as ever." ${ }^{(9, \text { p. } 951)}$

${ }^{1}$ IEFE Università Bocconi, Milan, Italy.

${ }^{2}$ Department of Decision Sciences, ELEUSI, Università Bocconi, Milan, Italy.

${ }^{3}$ Department of Economics Management and Quantitative Methods (DEMM), Milan, Italy.

${ }^{4}$ Department of Economics, Venice, Italy.

*Address correspondence to Emanuele Borgonovo, Department of Decision Sciences, Bocconi University, Via Roentgen 1, 20136 Milan, Italy; emanuele.borgonovo@unibocconi.it.
When environmental and climate change issues are considered, integrated assessment models (IAMs) play a central role in supporting the formulation of mitigating strategies and risk management plans. This practice is not free from criticism. ${ }^{(10,11)}$ Yet, scientific models are today's intermediaries between science and policy. ${ }^{(12)}$ IAMs, however, are very complicated machines due to the variety of features they capture and to the intricacy of the phenomena under investigation. It is then virtually impossible to have a direct understanding of the relationship between the endogenous and exogenous variables. Nonetheless, the literature highlights that "the standard of quality for models must be high, lest model use falls into disrepute and stakeholders reject the use of models altogether."(13, p. 302)

As underlined in Oppenheimer et al., ${ }^{(14)}$ the climate change community is aware of this instance: "dealing consistently with risk and uncertainty across the Intergovernmental Panel on Climate Change (IPCC) reports is a difficult challenge" $(15$, p. 3) and that "observed differences in handling uncertainties by the three IPCC working groups emerge." (15, p. 1)

How can we overcome these problems? Webster (16, p. 37) argues that "part of the solution 
is for the community to produce more instances of rigorous analysis of uncertainty for their respective models and projections." The U.S. Environmental Protection Agency recommends that model developers and users perform sensitivity and uncertainty analysis to help determine when a model can be appropriately used to inform a decision. ${ }^{(17)}$ As an essential step of its auditing process, ${ }^{(18,19)}$ the Florida Commission on Hurricane Loss Projection Methodology requires "uncertainty and sensitivity analyses to be performed with the applicant's proprietary model." (18, p. 1277)

Although "the judicious application of sensitivity analysis techniques appears to be the key ingredient needed to draw out the maximum capabilities of mathematical modeling,"(20, p.221) surveys show that the application of the most recently developed methods is quite limited in the field of climate change economics. Saltelli and Annoni(21) review several papers published in prominent scientific journals, such as Science and Nature, and conclude that the most widely utilized methods are one-factor-at-a-time (OFAT) techniques. OFAT methods evaluate the impacts of changes in exogenous variables varied one at a time. Though widespread, these methods are quite inadequate for identifying the exogenous variables on which to focus scientists' or decisionmakers' attention in the presence of uncertainty. Moreover, they do not allow analysts to appreciate the relevance of interactions.

OFAT methods were used in the series of rebuttals among Dietz et al., ${ }^{(22,23)}$ Nordhaus, ${ }^{(24,25)}$ Stern and Taylor, ${ }^{(26)}$ and Tol and Yohe. ${ }^{(27,28)}$ Weitzman $^{(29)}$ focuses on the sensitivity of endogenous variables primarily to the choice of the discount rate and to a few other selected exogenous variables. Saltelli and d'Hombres $^{(13)}$ offer a detailed analysis of the debate and conclude that, because only OFAT methods were used, sensitivity analysis (SA) did not help analysts in supporting their conclusions.

In fact, the task is challenging. On the one hand, we need methods that minimize the computational burden. On the other hand, the same methods must be robust and take all sources of uncertainty into account.

In this article, we argue that an answer to these challenges comes from a combined use of global sensitivity methods together with recent advances in their estimation. We demonstrate that insights concerning direction of change, model structure, and key uncertainty drivers can be directly extracted from the sample generated by a traditional Monte Carlo simulation, avoiding the need of ad hoc numerical experiments and with a notable reduction in computational burden. Our method builds on the highdimensional model representation (HDMR) theory of Rabitz and Alis. ${ }^{(30)}$ The HDMR theory allows us to understand whether the endogenous variable response to changes in the exogenous variables is equal to the sum of their individual effects or whether interactions are also relevant. It also allows us to appraise the direction of change (the fundamental question of comparative statics) in a global sense, as opposed to the local information provided by traditional comparative statics. The methodology is then complemented by the use of density-based methods for the identification of key uncertainty drivers in the presence of both correlated and uncorrelated exogenous variables.

The methodology is illustrated using one of the best-known IAMs, Nordhaus's DICE model. The findings show that the method provides several crucial insights to both analysts and policymakers. Furthermore, we obtain a systematic identification of the exogenous variables and areas on which to focus additional information collection and/or modeling efforts.

The remainder of the article is organized as follows. Section 2 reviews the existing literature and provides a brief snapshot of how global sensitivity analysis methods are, or are not, used. Section 3 presents our proposed methodology, whose estimation and computation aspects are considered in Section 4. The global SA methodology is then applied on the DICE model and the results of this exercise are presented in Section 5. Concluding remarks close the article.

\section{A CURSORY LITERATURE REVIEW ON IAMS AND THEIR UNCERTAINTY ANALYSIS}

Most and Keles ${ }^{(31)}$ highlight that policymakers increasingly benefit from the utilization of decisionsupport models. Their observations are in line with the earlier statements of Jannsen, ${ }^{(32)}$ who underlines that the IPCC "is placing increasing emphasis on the use of dynamic or time-dependent simulation models to assess the effects of global climate change."(32, p. 22) The models developed to support decision making in the climate change arena are numerous. Gametheoretic models for climate negotiations are discussed in Forgó et al. ${ }^{(33)}$ An important role is played by the market allocation (MARKAL) model, ${ }^{(34)}$ a 
linear programming model for energy market planning. A modified version of MARKAL is used to find optimal responses in long-term energy planning in view of alternative climate change patterns for the Quebec region. ${ }^{(35)}$ A model for the robust determination of optimal energy technology research and development investment programs in consideration of the effects of climate change is developed in Baker and Solak. ${ }^{(36)}$

A prominent class of models is represented by IAMs. Aside from their traditional use of evaluating the long-term implications of climate-economy interactions, IAMs are also becoming increasingly used as a tool to study how uncertainty and ambiguity affect policymakers' decisions regarding climate change. Golub et al. ${ }^{(37)}$ provide a comprehensive overview of different approaches used to model uncertainty when applying IAMs. Millner et al. ${ }^{(38)}$ Lemoine and Traeger, ${ }^{(39)}$ and Iverson and Perrings ${ }^{(40)}$ are recent examples of applications using the DICE model to study these areas of decision science.

The list of studies covered by $\mathrm{Tol}^{(41)}$ in his metaanalysis of alternative estimates of the social cost of carbon shows that three IAMs emerge as the most widely applied and commonly cited in the literature: Richard Tol's FUND, Chris Hope's PAGE, and the DICE model of William Nordhaus.

Many of the cited studies in Tol ${ }^{(41)}$ acknowledge the existence of uncertainty and attempt to perform some type of SA. This is usually accomplished by altering the values of a certain targeted exogenous variable, often the discount rate and/or climate sensitivity, to test the values of the endogenous variables under different scenarios. The tendency is, therefore, to answer specific sensitivity questions, and not to let the model undergo a systematic investigation through global SA.

At the same time, Monte Carlo simulation is becoming part of best practices in the IAM. It has been used for an uncertainty analysis of the DICE model $^{(42,43)}$ and in different vintages of the PAGE model. ${ }^{(44)}$ It is employed in a recent study by Dietz ${ }^{(45)}$ in an assessment of catastrophic climate change based on the PAGE model and by Nordhaus and Popp $^{(46)}$ using DICE and Popp ${ }^{(47)}$ using ENTICE, an extension of the DICE model. Monte Carlo simulation is also used in Dietz and Asheim ${ }^{(48)}$ in their work on sustainable discounted utilitarianism, where it accompanies the risk analysis of a modified version of DICE. Monte Carlo simulation (sometimes called uncertainty analysis) conveys to decisionmakers the uncertainty in model predictions, avoiding the risk of overconfidence in model forecasts. However, for a full understanding and corroboration of model results, analysts ought to identify the exogenous variables that influence the model results the most (key drivers), the direction of change associated with the variation of a given exogenous variable, and the overall model structure (interaction analysis).

We are aware of only three studies devoted to the application of methods similar to the ones proposed in this article to investigate the effects of uncertainty on IAMs. Van Vuuren et al. ${ }^{(49)}$ apply a probabilistic approach to an energy model, Hof et $a l .{ }^{(50)}$ use the FAIR IAM, and the effects of uncertainty on the social cost of carbon using the FUND model are explicitly addressed in Anthoff and Tol. ${ }^{(51)}$ In all cases, Monte Carlo simulations are used to propagate uncertainty and the results of those simulations are postprocessed using either raw correlations or standardized regression coefficients to signal the magnitude of the impact that uncertainty in the exogenous variables has on the endogenous variables produced by the model. The SA literature clearly describes the weaknesses of using correlations or standardized regression coefficients as a methodology for postprocessing the Monte Carlo results. These limitations are mainly linked to their poor performance in the presence of nonlinearities and of interactions, ${ }^{(52)}$ so that several authors have argued in favor of the utilization of more robust methods. ${ }^{(30,53,54)}$

\section{GLOBAL SENSITIVITY ANALYSIS: SETTINGS AND METHODS}

Global sensitivity analysis methods give full credit to our uncertainty about the values of the exogenous variables. The first step of a global SA consists of propagating uncertainty throughout the model (this process is called uncertainty analysis) by estimating the distribution of endogenous variables from the distribution of exogenous variables. An endogenous variable $(y)$ is linked to exogenous variables by some kind of mathematical relationship. Formally:

$$
y=g(\mathbf{x}): \Omega_{X} \subseteq \mathbb{R}^{n} \rightarrow \mathbb{R},
$$

where $g(\mathbf{x})$ is the exogenous-endogenous variable mapping, $\Omega_{X} \subseteq R^{n}$ is the set of possible values that the exogenous variables can assume, and $\mathbf{x}$ is one of the possible values of the uncertain exogenous variables. In global sensitivity analysis, we assume to have information about the exogenous variables' "probability distribution, either joint or marginal, with or without correlation, and that this knowledge comes from measurements, estimates, 
expert opinion, physical bounds, output from simulations, ...." (56. p. ${ }^{704)}$ Let $F_{X}(\mathbf{x})$ denote the joint probability distribution function of the exogenous variables. Through Monte Carlo simulation a sample of size $N$ is produced, so that in each model run the exogenous variables follow the distribution corresponding to $F_{X}(\mathbf{x})$. Various sampling generation methods are available; see Helton and Davis ${ }^{(55)}$ for a thorough overview. To obtain the corresponding distribution of the endogenous variable, the model is evaluated $N$ times in correspondence of the realized values of the exogenous variables. Uncertainty analysis allows us to assess the distribution of the endogenous variable. We let $F_{Y}(y)$ denote the cumulative distribution function of the endogenous variable $Y$ (henceforth, capital letters denote random variables, lower case letters one of their realizations). Knowledge of $F_{Y}(y)$ permits analysts to estimate all relevant moments and percentiles of $Y$ and is also essential in computing risk measures.

Global SA integrates and complements uncertainty analysis providing analysts with additional and crucial information. Several methods have been developed and several are the insights that analysts can draw from global SA methods. Saltelli and Tarantola ${ }^{(56)}$ introduce the concept of SA "setting." A setting is a way to frame the SA quest so as to clearly identify its objectives. ${ }^{(54,57)}$ In this article, we carry out our analysis in accordance with the following settings: ${ }^{(58)}$

(1) Model structure: to determine whether the endogenous variable behavior is the result of the superimposition (addition) of individual effects or it is driven by their interactions;

(2) Direction of change: to determine what is the expected direction of change in the endogenous variable due to individual or simultaneous changes in the exogenous variables; and

(3) Exogenous variable prioritization: to determine the key uncertainty drivers, namely, the exogenous variables, on which resources should be focused in data and information collection to most effectively reduce the variability in a model's predictions.

We now discuss each of these settings in turn.

\subsection{Model Structure}

Understanding the structure of an exogenousendogenous variable mapping requires the assess- ment of interactions. Assume that $g(\mathbf{x})$ is integrable (thus, in principle, even nonsmooth). Then, $g(\mathbf{x})$ can be written exactly as: ${ }^{(30,53,59)}$

$$
\begin{aligned}
y=g(\mathbf{x})= & g_{0}+\sum_{i=1}^{n} g_{i}\left(x_{i}\right)+\sum_{i<j}^{n} g_{i, j}\left(x_{i}, x_{j}\right)+\cdots \\
& +g_{1,2, \ldots, n}\left(x_{1}, x_{2}, \ldots, x_{n}\right)
\end{aligned}
$$

where

$$
\left\{\begin{array}{l}
g_{0}=E_{\mathbf{X}}[g(\mathbf{x})]=\int \cdots \int g(\mathbf{x}) \prod_{i=1}^{n} d F_{i} \\
g_{i}\left(x_{i}\right)=E_{\mathbf{X}}\left[g(\mathbf{x}) \mid X_{i}=x_{i}\right]-g_{0}=\int \cdots \\
\int g(\mathbf{x}) \prod_{s=1, s \neq i}^{n} d F_{s} g_{i, j}\left(x_{i}, x_{j}\right)=E_{\mathbf{X}}\left[g(\mathbf{x}) \mid X_{i}=x_{i},\right. \\
\left.X_{j}=x_{j}\right]-g_{i}\left(x_{i}\right)-g_{j}\left(x_{j}\right)-g_{0} \\
=\int \cdots \int g(\mathbf{x}) \prod_{s=1, s \neq i, j}^{n} d F_{s} \cdots \\
g_{1,2, \ldots n}\left(x_{1}, x_{2}, \ldots x_{n}\right) \\
=E_{X}\left[g(x) \mid X_{1}=x_{1}, \ldots X_{n}=x_{n}\right] \\
-\sum_{k=1}^{n} \sum_{i_{1}<i_{2}<\cdots<i_{k}} g_{k}\left(x_{i_{1}}, x_{i_{2}}, \ldots, x_{i_{k}}\right)-g_{0}
\end{array}\right.
$$

Equation (2) is called the HDMR of $g(\mathbf{x}) .^{(30)}$ In Equation (3), $g_{0}$ is the average value of $y$ over $\Omega_{Y} ; g_{i}\left(x_{i}\right)$ accounts for the individual effect of $X_{i}$; $g_{i, j}\left(x_{i}, x_{j}\right)$ accounts for the interactions of exogenous variables $X_{i}, X_{j}$, and so on. Equation (2) states that $g(\mathbf{x})$ is exactly reconstructed by the sum of the functions on the right-hand side of Equation (3). Equations (2) and (3) provide the multivariate "integral" expansion of $g(\mathbf{x})$.

Assume now that $g(\mathbf{x})$ is square integrable. Then, by the orthogonality of the functions in Equation (3), subtracting $g_{0}$ from $g(\mathbf{x})$ and squaring, one obtains the complete decomposition of the variance of $Y$ :

$$
V[Y]=\sum_{i=1}^{n} V_{i}+\sum_{i<j}^{n} V_{i j}+\cdots+V_{1,2, \ldots, n},
$$

where

$$
\left\{\begin{array}{l}
V_{i}=\int g_{i}^{2} \mathrm{~d} F_{i} \\
V_{i, j}=\iint g_{i, j}^{2} \mathrm{~d} F_{i} \mathrm{~d} F_{j} \\
\quad \cdots \\
V_{1,2, \ldots n}=\int \cdots \int g_{1,2, \ldots n}^{2} d F_{1} d F_{2} \cdots d F_{n}
\end{array}\right.
$$

On the basis of Equations (4) and (5), one introduces the sensitivity measures of order $z(z=$ $1,2, \ldots, n)$ defined as: ${ }^{(53)}$

$$
S_{i, j, \ldots, k}^{z} \equiv \frac{V_{i, j, \ldots, k}^{z}}{V[Y]},
$$


where the set $\{i, j, \ldots, k\}$ is any group of $z$ indices. $S_{i, j, \ldots, k}^{z}$ provides the relevance of the interaction among exogenous variables in group $i, j, \ldots, k$. Special attention is deserved by the first $\left(S_{l}^{1}\right)$ and the total order $\left(S_{l}^{T}\right)$ sensitivity measures of exogenous variable $X_{l}$, defined, respectively, as: ${ }^{(60)}$

$$
S_{l}^{1} \equiv \frac{V_{l}}{V[Y]}=\frac{V_{X_{l}}\left[E_{\mathbf{X}_{\sim}}\left\{Y \mid X_{l}\right\}\right]}{V[Y]} \quad(l=1, \ldots, n),
$$

and

$$
S_{l}^{T}=\frac{E_{\mathbf{X}_{\sim}}\left[V_{X_{l}}\left\{Y \mid \mathbf{X}_{\sim l}\right\}\right]}{V[Y]} \quad(l=1, \ldots, n) .
$$

In Equation (8), the symbol $\mathbf{X}_{-l}$ denotes all exogenous variables but $X_{l}$. Thus, $S_{l}^{1}$ is the fraction of $V^{(} Y^{)}$outstanding after $X_{l}$ has been fixed, whereas $S_{l}^{T}$ is the fraction of $V^{(} Y^{\prime}$ remaining after all exogenous variables are fixed but $X_{l}$. Disentangling the contribution of single exogenous variables and of interactions to the overall model variability (Setting 1) is quite naturally addressed by applying the functional ANOVA decomposition and the associated sensitivity measures reported in Equations (6)-(8).

The sum of variance-based sensitivity measures provides indication on the structure of $g(\mathbf{x})$. If ${ }_{i=1}^{n} S_{i}^{1}=1$, the model is additive, that is, its response is the exact addition of the individual effects of the exogenous variables. Conversely, if $\sum_{i=1}^{n} S_{i}^{1}<1$, interaction effects are present. The lower the sum of the first-order indices, the higher the relevance of interactions.

\subsection{Direction of Change}

Direction of change in the endogenous variable following variations in one of the exogenous variables (Setting 2) can be addressed through the investigation of functions $g_{0}+g_{i}\left(x_{i}\right)$. Note that, from the second equation in (3), we have:

$$
E\left[g(x) \mid X_{i}=x_{i}\right]=g_{i}\left(x_{i}\right)+g_{0} .
$$

Hence, the one-dimensional function $g_{0}+g_{i}\left(x_{i}\right)$ represents the conditional expectation of $g(x)$ as a function of $x_{i}$. In particular, if $g(x)$ is additive, then $g_{i}\left(x_{i}\right)+g_{0}$ expresses the exact dependence of $Y$ on $X_{i}$. Thus, we are able to understand whether $Y$ is a monotonic function of $X_{i}$ with no approximation and for all values of $X_{i}$. If $g(x)$ is not additive, then Equation (9) allows us to understand the dependence of
$Y$ on $X_{i}$ as all possible values of the remaining exogenous variables are averaged. In this simultaneous variation lies the difference between comparative statics in the sense of Samuelson ${ }^{(61)}$ and comparative statics performed using an integral approach. By differential comparative statics one obtains a local information, namely, the variation rate of $Y$ around a given point in the exogenous variable space for a small variation in $X_{i}$. In a global SA, one instead obtains information about what happens to $g(x)$ as $X_{i}$ varies over its entire range and while all other exogenous variables change simultaneously.

\subsection{Factor Prioritization}

The identification of key uncertainty drivers (Setting 3) may appear to be linked to the discussion above on variance decomposition, suggesting that a critical exogenous variable could be the one that has a significant impact on the endogenous variable(s) variance. However, it is well known that variance is not a summary of uncertainty when distributions are skewed or multimodal. Moreover, when exogenous variables are correlated, which is likely to be the case in many natural phenomena, variance-based sensitivity measures lose their link to the functional ANOVA decomposition. These two cases are frequently encountered in the climate change literature. Therefore, we adopt, in addition to a variance-based approach, the $\delta$ sensitivity measure ${ }^{(62,63)}$ defined as follows:

$$
\delta_{l}=\frac{1}{2} E_{l}\left[a_{l}\left(x_{l}\right)\right]
$$

where

$$
a_{l}\left(x_{l}\right)=\left|f_{Y}(y)-f_{Y \mid X_{l}=x_{l}}(y)\right| .
$$

$a_{i}\left(x_{i}\right)$ measures the separation ("distance") between the unconditional distribution of the endogenous variable $\left(f_{Y}(y)\right)$ and its conditional distribution given that exogenous variable $X_{i}$ is fixed at $x_{i}\left(f_{Y \mid X_{i}=x_{i}}(y)\right)$. Geometrically, $a_{i}\left(x_{i}\right)$ is the area enclosed between $f_{Y}(y)$ and $f_{Y \mid X_{i}=x_{i}}(y)$.

$\delta$ possesses several convenient properties. The ones of major interest here are (i) normalization to unity, ${ }^{(63)}$ that is, $0 \leq \delta_{i} \leq 1,(i=1,2, \ldots, n)$, and (ii) monotonic transformation invariance, ${ }^{(64)}$ that is, if $u(Y)$ and $t(Y)$ are two monotonic functions of $Y$, then $\delta_{i}^{u(Y)}=\delta_{i}^{t(Y)}=\delta_{i}^{Y}$. The first property states that each exogenous variable is associated with an "importance index," which lies between 0 and 1 . Moreover, it is proven in Plischke et al. ${ }^{(65)}$ that $\delta_{i}=0$ if and 
only if $Y$ and $X_{i}$ are independent. Thus, $\delta_{i}$ is a measure of statistical dependence, rather than of functional dependence as are variance-based sensitivity measures. The second property, monotonic transformation invariance, is desirable for two aspects, numerical and theoretical. In several environmental applications, the output of a Monte Carlo simulation is sparse or spans a wide range. This could bring about inaccurate estimation of sensitivity measures. To improve numerical precision, analysts often resort to a transformation of the endogenous variable (usually, a log-transformation). Monotonic transformation invariance ensures that after any monotonic transformation, the results of SA remain unaltered. The second reason is that in many applications the endogenous variable is a utility function. It is a well-known principle of economic theory that utility functions have an ordinal, not cardinal, meaning, so that they can be modified through monotonic transformations. Monotonic transformation invariance, then, ensures that results of the sensitivity analysis remain valid for any chosen monotonic utility function. For further discussion on the decision-making implications of this result, see Baucells and Borgonovo. ${ }^{(66)}$

\section{ESTIMATION AND COMPUTATIONAL COST}

The estimation of the sensitivity measures proposed above is analytically feasible only in very few instances and with simple mathematical expressions that usually do not represent an environmental or economic problem. For IAMs, which are complex simulation tools encoded in dedicated software, the estimation is numerical. The cost of the analysis is measured in number of model runs. Thus, the cost of an uncertainty analysis is $C^{M C S}=N$, where $N$ is the sample size of a Monte Carlo simulation.

An algorithm that strictly reproduces the definitions in Equations (7), (8), and (10) - brute force estimation-is associated with a computational cost $\left(C^{G S A}\right)$ equal to

$$
C^{G S A}=N n^{2}
$$

model runs, where $n$ is the number of exogenous variables. $N$ is chosen by analysts in such a way to ensure estimation accuracy. The dependence on $n^{2}$ makes the computational cost increase rapidly with model size.

However, a series of contributions ${ }^{(67-69)}$ have led to a drastic reduction in the estimation of variance- based indices, lowering $C^{G S A}$ to

$$
C^{G S A}=N(n+2)
$$

model runs for estimating all first- and total-order sensitivity measures. The sampling plans in Castaings et al. ${ }^{(70)}$ lower the computational cost of the $\delta$-importance measure to;

$$
C^{G S A}=r N,
$$

where $r$ is the number of replicates.

Note that an analyst pursuing these estimation strategies has to run two different sets of numerical experiments, a first one to estimate $S_{l}^{1}$ and $S_{l}^{T}$ and a second one to estimate $\delta_{l}$. However, recent works have led to additional computational burden reductions, lowering $C^{G S A}$ to:

$$
C^{G S A}=N=C^{M C S} .
$$

There are two main ways to achieve this result. The first foresees making use of a meta-model (or emulator). Kriging, ${ }^{(71)}$ Gaussian emulation, ${ }^{(72)}$ polynomial chaos expansion, ${ }^{(73,74)}$ state-dependent parameter modeling, ${ }^{(75)}$ and the Cut-HDMR ${ }^{(30,76)}$ are among the most widely used methods. For instance, in the Cut-HDMR approach the meta-model allows the estimation of Sobol's sensitivity measures of orders 1 and 2 from the component functions $g_{i}\left(x_{i}\right)$ and $g_{i, j}\left(x_{i}, x_{j}\right)$, which are obtained by fitting orthonormal bases, through a system of equations of the type: ${ }^{(76)}$

$$
\begin{gathered}
g_{i}\left(x_{i}\right) \approx \sum_{r=1}^{h} \alpha_{r}^{i} \phi_{r}\left(x_{i}\right) \\
g_{i, j}\left(x_{i}, x_{j}\right) \approx \Sigma_{p=1}^{h^{\prime}} \Sigma_{q=1}^{h^{\prime \prime}} \beta_{p, q}^{i, j} \phi_{q}\left(x_{i}\right) \phi_{q}\left(x_{i}\right),
\end{gathered}
$$

where $\phi_{r}\left(x_{i}\right)$ is an element of a family of orthonormal polynomials, $\alpha_{r}^{i}$ and $\beta_{p, q}^{i, j}$ are the corresponding coefficients, and $h, h \prime$, and $h^{\prime \prime}$ determine the order of the expansion (see Ziehn and Tomlin ${ }^{(76)}$ for further details).

The second way is to utilize orthogonal projections and is used in Plischke et al. ${ }^{(65)}$ This technique allows one to estimate variance-based sensitivity measures and $\delta_{l}$. The method consists of a reordering of the data set to form a scatterplot $X_{i} \oplus y$, followed by a partitioning of the data set. The method works as a postprocessing algorithm and the estimation is direct, without the need of a metamodel.

The advantage of combining the proposed approaches is that analysts can obtain all the discussed insights from the data set produced by Monte Carlo simulation, without the need to resort to an ad hoc 
sampling scheme. In summary, the overall procedure consists of the following steps:

(1) Assign a distribution to the $n$ model exogenous variables;

(2) Generate the corresponding sample of model exogenous variables $\widehat{A}, \widehat{A}$ is a matrix of size $n$ $\times N$

(3) Perform uncertainty analysis evaluating the model $N$ times, obtaining the corresponding endogenous variable vector $\widehat{Y}$;

(4) Consider the data set $[\widehat{A} \widehat{Y}]$; and

(5) Postprocess the data set to obtain insights into model structure, monotonicity, and key uncertainty drivers.

In this article, we shall make use of the CutHDMR meta-model ${ }^{(76)}$ and of Plischke et al.'s ${ }^{(65)}$ method to respond to the three sensitivity settings spelled out in Section 3: (i) model structure, through knowledge of the variance-based sensitivity indices, and of the $g_{i, j}\left(x_{i}, x_{j}\right)$ functions; (ii) monotonicity, by plotting the main effect functions $g_{i}\left(x_{i}\right)$; and (iii) key uncertainty drivers, by estimating $\delta_{l}$.

\section{GLOBAL SENSITIVITY ANALYSIS OF THE DICE MODEL}

DICE is one of the most widely acknowledged IAMs due to the expertise of William Nordhaus, "whose careful pragmatic modeling throughout his DICE series of IAMs has long set a standard."(29, p. 713) Nordhaus $^{(43)}$ characterizes the DICE model as "a global model that aggregates different countries into a single level of output, capital stock, technology, and emissions. The estimates for the global aggregates are built up from data that include all major countries, and the specification allows for differentiated responses and technological growth." (43, p. 33) DICE has been evolving since the early 1990s with many refinements and adaptations to answer specific research questions. Jannsen ${ }^{(32)}$ combines the economic part of DICE with the mathematical part of IMAGE-an integrated model to assess greenhouse effect-to obtain the OMEGA code (optimization model for economic and greenhouse assessment). Nordhaus and Popp ${ }^{(46)}$ use PRICE, a probabilistic version of the DICE model. Keller et al. ${ }^{(77)}$ modify DICE for assessing the impact of uncertainties and learning about climate thresholds. A stochastic version of DICE is used by McInerney and Keller ${ }^{(78)}$ to support the assessment of mitigation strategies. McInerney et al. ${ }^{(79)}$ employ a modified version of DICE to assess how alternative decision-making criteria (precisely expected utility maximization, safety first, and limited degree of confidence) "affect preferred investments into greenhouse gas mitigation."(79,p.1) Most recently, DICE is used in the comparison of the info-gap versus robust decision-making approaches for decision making under uncertainty. ${ }^{(3)}$ As mentioned in Section 2, DICE has been utilized in the context of sustainable utilitarianism. ${ }^{(48)}$ Popp $^{(47)}$ develops a model based on DICE with endogenous technical change (ENTICE). A multiregion variant of DICE, called RICE, has been developed by Nordhaus and Yang. ${ }^{(80)}$ RICE has been used in various amended forms by, among others, Eyckmans and Tulkens, ${ }^{(81)}$

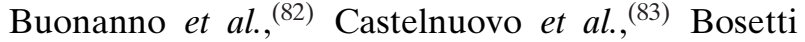
et al. ${ }^{(84)}$ de Bruin et al. ${ }^{(85)}$ and Bosello and Chen. ${ }^{(86)}$ The 2010 version of RICE is succinctly described in Nordhaus. ${ }^{(92)}$

We use Version 2007.delta.8 of DICE (http:// nordhaus.econ.yale.edu/DICE2007'short.gms). We do not go into details concerning the equations of the model. They are comprehensively described in Nordhaus $^{(43)}$ and one can find synthetic descriptions in Jannsen, ${ }^{(32)}$ Dietz and Asheim, ${ }^{(48)}$ and Keller at $a l .{ }^{(77)}$ We limit ourselves to note that the exogenousendogenous variable mapping is composed of a series of interconnected equations (or submodels) that generate multiple outputs. These endogenous variables depend on 51 exogenous variables, which are reported in Table I (acronyms are the same as the original ones; see http://nordhaus.econ.yale.edu/ DICE2007'short.gms).

Among the many endogenous variables produced by DICE, we focus on intergenerational utility, the social cost of carbon in 2005, global atmospheric temperature in 2105, the level of global emissions in 2105, and the optimal carbon tax for 2015. The reason for these choices is twofold: they are relevant for policy purposes and they grant comparison with previous SA performed using the same model. ${ }^{5}$

\footnotetext{
${ }^{5}$ The social cost of carbon represents the economic cost caused by an additional ton of carbon emissions. The cost is the monetary impact on the discounted intergenerational utility of consumption. Mathematically, the social cost of carbon is the shadow price of carbon emissions along a reference path, typically the actual path, of output or emissions. As noted by Nordhaus, ${ }^{(92)}$ in an optimized climate policy, the social cost of carbon will equal the carbon price or the carbon tax; in an uncontrolled regime, the social cost of carbon will generally exceed the (zero) carbon price.
} 
Table I. DICE 2007 Exogenous Variables

\begin{tabular}{|c|c|c|c|}
\hline$\#$ & Acronym & Description & Name Used in Text \\
\hline 1 & A0 & Initial level of total factor productivity & Initial productivity \\
\hline 2 & A1 & Damage function linear factor & Damage function linear factor \\
\hline 3 & A2 & Damage function exponential factor & Damage function exponential factor \\
\hline 4 & A3 & Damage function exponent & Damage function exponent \\
\hline 5 & BACKRAT & Ratio initial to final backstop cost & \\
\hline 6 & B'ELASMU & Elasticity of marginal utility of consumption & Elasticity of marginal utility of consumption \\
\hline 7 & B'PRSTP & Initial rate of social time preference per year & Initial rate of social time preference per year \\
\hline 8 & $\mathrm{C} 1$ & Climate equation coefficient for upper level & Climate equation coefficient for upper level \\
\hline 9 & C3 & Transfer coefficient upper to lower stratum & \\
\hline 10 & $\mathrm{C} 4$ & Transfer coefficient for lower level & \\
\hline 11 & DELA & Decline rate of technological change per decade & \\
\hline 12 & DK & Depreciation rate on capital per year & \\
\hline 13 & DPARTFRACT & Decline rate of participation & \\
\hline 14 & DSIG & Decline rate of decarbonization per decade & \\
\hline 15 & DSIG2 & Quadratic term in decarbonization & \\
\hline 16 & ELAND0 & Carbon emissions from land 2005 (GtC per decade) & \\
\hline 17 & EXPCOST2 & Exponent of control cost function & Control function exponent \\
\hline 18 & $\mathrm{FCO} 22 \mathrm{X}$ & Estimated forcings of equilibrium $\mathrm{CO}_{2}$ doubling & Estimated forcings of equilibrium $\mathrm{CO}_{2}$ doubling \\
\hline 19 & FEX0 & Estimate of 2000 forcings of non- $\mathrm{CO}_{2} \mathrm{GHG}$ & \\
\hline 20 & FEX1 & Estimate of 2100 forcings of non- $\mathrm{CO}_{2} \mathrm{GHG}$ & \\
\hline 21 & FOSSLIM & Maximum cumulative extraction of fossil fuels & Cumulative fossil fuel extraction \\
\hline 22 & GA0 & Initial growth rate for technology per decade & Growth in total factor productivity \\
\hline 23 & GAMA & Capital elasticity in production function & Elasticity of capital \\
\hline 24 & GBACK & Initial cost decline backstop pc per decade & Initial cost decline backstop pc per decade \\
\hline 25 & GPOP0 & Growth rate of population per decade & \\
\hline 26 & GSIGMA & Initial growth of sigma per decade & Initial sigma growth \\
\hline 27 & K0 & 2005 value capital trillion 2005 US dollars & 2005 value capital \\
\hline 28 & LIMMIU & Upper limit on control rate & \\
\hline 29 & MAT2000 & Concentration in atmosphere 2005 (GtC) & Concentration in atmosphere 2005 \\
\hline 30 & ML2000 & Concentration in lower strata 2005 (GtC) & \\
\hline 31 & MU2000 & Concentration in upper strata 2005 (GtC) & \\
\hline 32 & PARTFRACT1 & Fraction of emissions under control regime 2005 & \\
\hline 33 & PARTFRACT2 & Fraction of emissions under control regime 2015 & \\
\hline 34 & PARTFRACT21 & Fraction of emissions under control regime 2205 & \\
\hline 35 & PBACK & Cost of backstop 2005 per tC 2005 & Cost of backstop in 2005 \\
\hline 36 & POP0 & 2005 world population millions & \\
\hline 37 & POPASYM & Asymptotic population & Asymptotic population \\
\hline 38 & Q0 & 2005 world gross output trillion 2005 US dollars & \\
\hline 39 & SIG0 & $\mathrm{CO}_{2}$-equivalent emissions-GNP ratio 2005 & Emissions-GNP ratio \\
\hline 40 & $\mathrm{~T} 2 \mathrm{XCO} 2$ & Equilibrium temperature impact of $\mathrm{CO}_{2}$ doubling $\mathrm{C}$ & Climate sensitivity \\
\hline 41 & TATM0 & 2000 atmospheric temperature change (C) from 1900 & \\
\hline 42 & TOCEAN0 & 2000 lower stratospheric temperature change (C) from 1900 & \\
\hline 43 & b11 & Carbon cycle transition matrix & $\mathrm{b}_{11}$ in carbon cycle transition matrix \\
\hline 44 & b12 & Carbon cycle transition matrix & $\mathrm{b}_{12}$ in carbon cycle transition matrix \\
\hline 45 & $\mathrm{~b} 21$ & Carbon cycle transition matrix & $\mathrm{b}_{21}$ in carbon cycle transition matrix \\
\hline 46 & b22 & Carbon cycle transition matrix & $\mathrm{b}_{21}$ in carbon cycle transition matrix \\
\hline 47 & $\mathrm{~b} 23$ & Carbon cycle transition matrix & $\mathrm{b}_{23}$ in carbon cycle transition matrix \\
\hline 48 & b32 & Carbon cycle transition matrix & $\mathrm{b}_{32}$ in carbon cycle transition matrix \\
\hline 49 & b33 & Carbon cycle transition matrix & $\mathrm{b}_{33}$ in carbon cycle transition matrix \\
\hline 50 & scale1 & Scaling coefficient in the objective function & \\
\hline 51 & scale2 & Scaling coefficient in the objective function & \\
\hline
\end{tabular}

Note: The acronym of each variable is the same as in the original DICE code (see http://nordhaus.econ.yale.edu/DICE2007 short.gms). 
Indeed, these are the variables directly looked at by Nordhaus ${ }^{(43)}$ himself.

The presentation of the results of our global SA exercise is divided in two parts. The first part describes the set of results stemming from a comparison of our methodology with the sensitivity analysis of the DICE model directly performed by Nordhaus, ${ }^{(43)}$ where only eight preselected exogenous variables are subject to the analysis. The second set presents results for the data set obtained when uncertainties in all exogenous variables are considered.

\subsection{A Comparative Analysis}

Our reference point is the sensitivity analysis of the DICE model performed in Chapter 7 of Nordhaus. ${ }^{(43)}$ Nordhaus $^{(42)}$ identifies eight exogenous variables as key uncertainty drivers. "On the basis of earlier studies using the DICE model, as well as studies by other scholars, we have selected eight of the major exogenous variables in the DICE model for further study ...."(43, p. 125) For the time being, we take for granted the outcome of the selection exercise and use the same probability distributions for the eight exogenous variables as in Nordhaus ${ }^{(43)}$ in order to provide a comparison with the insights that can be obtained by applying the methods discussed in this article.

To determine the importance of the exogenous variables Nordhaus ${ }^{(43)}$ then follows an OFAT method. ${ }^{6}$ The exogenous variables are varied one at a time from one up to six standard deviations from the assumed mean value. The results are presented in Tables 7-2 and 7-3 of Nordhaus. ${ }^{(43)}$ We report them in Table II for clarity and to facilitate comparison.

Table II reads as follows: consider the first column in the upper portion. When the value of the growth in total factor productivity (GA0) is altered by one standard deviation, the value of social cost of carbon increases to $\$ 36.07$, a $28 \%$ increase from the mean value. Table II shows that for the social cost of carbon in 2005, the exogenous variable damage function exponential factor (A2)-which is the exponential factor of the quadratic term of the damage function (see Table I) - has the largest effect as $k$ (i.e., the distance from the mean value) varies. ${ }^{7}$ Indeed, the damage function exponential factor is al-

\footnotetext{
${ }^{6}$ See Nordhaus, ${ }^{43, \text { p. }}{ }^{129)}$ Section "Importance of Different Uncertainties" of Chapter 7.

${ }^{7}$ The damage function is a critical component of all IAMs. The specification used in DICE expresses the loss of potential GDP
}

ways the most influential exogenous variable, regardless of the distance from its mean value. Conversely, at one standard deviation $(k=1)$, climate sensitivity (T2XCO2) is ranked third behind the growth in total factor productivity in the magnitude of the change from the mean value, but the ranking is reversed at two standard deviations from the mean value $(k=2)$ and then again as $k$ gets larger.

This sensitivity exercise does not achieve the identification of the key uncertainty drivers because the ranking is not robust with respect to variations of the exogenous variables throughout their support. This reveals the mismatch between the analysts' state of knowledge (which implies uncertainty in the exogenous variables) and the sensitivity method used for the analysis (which is OFAT). However, based on the distributions assigned to the eight exogenous variables, Nordhaus ${ }^{(43)}$ performs an uncertainty analysis using Monte Carlo simulation and obtains the distributions of the endogenous variables. By postprocessing this data set using the algorithm of Plischke et al., ${ }^{(65)}$ we can assess the importance of the exogenous variables using our $\delta$ sensitivity indexes (Section 3.3). The corresponding ranking takes the assessed distributions completely into account and does not force us to inspect preselected deviations from the mean. Figs. 1 and 2 report results for the social cost of carbon and for global emissions, respectively.

At the top of each bar, the $90 \%$ confidence intervals obtained from 500 bootstrap replicates using the bias-reducing estimator proposed in Plischke et al. ${ }^{(65)}$ are displayed. The narrow confidence intervals show that the estimation is accurate and results can be trusted from a numerical viewpoint. For the social cost of carbon, damage function exponential factor, climate sensitivity (T2XCO2), and growth in total factor productivity are the most influential exogenous variables. The exogenous variables damage function exponential factor and climate sensitivity concur in the determination of the magnitude of climate change impacts. Moreover, as the impacts are expressed as a fraction of lost gross domestic product (GDP), the higher the growth rate of the economy, which is affected by the growth in total factor productivity, the larger the increase in the social cost of carbon. This is because this cost is the annualized value of all periodic losses, which are larger when GDP is higher. Examining global emissions, Table II

as the inverse of a quadratic function of the variation in atmospheric temperature. 
Table II. Summary of Nordhaus's (2008) Sensitivity Analysis Results

\begin{tabular}{|c|c|c|c|c|c|c|c|c|}
\hline $\begin{array}{l}\text { Standard } \\
\text { Deviation }\end{array}$ & $\begin{array}{l}\text { Growth in } \\
\text { Total Factor } \\
\text { Productivity }\end{array}$ & $\begin{array}{l}\text { Initial } \\
\text { Sigma } \\
\text { Growth }\end{array}$ & $\begin{array}{l}\text { Climate } \\
\text { Sensitivity }\end{array}$ & $\begin{array}{c}\text { Damage Function } \\
\text { Exponential } \\
\text { Factor }\end{array}$ & $\begin{array}{l}\text { Cost of } \\
\text { Backstop } \\
\text { in } 2005\end{array}$ & POPASYM & $\begin{array}{l}\text { b12 in Carbon } \\
\text { Transition } \\
\text { Matrix }\end{array}$ & $\begin{array}{l}\text { Cumulative } \\
\text { Fossil Fuel } \\
\text { Extraction }\end{array}$ \\
\hline \multicolumn{9}{|c|}{ Social Cost of Carbon 2005} \\
\hline 0 & $28.1(0)$ & $28.1(0)$ & $28.1(0)$ & $28.1(0)$ & $28.1(0)$ & $28.1(0)$ & $28.1(0)$ & $28.1(0)$ \\
\hline 1 & $36.07(28)$ & $28.27(1)$ & $38.07(35)$ & $40.99(35)$ & $28.1(0)$ & $32.14(14)$ & $29.16(4)$ & $28.1(0)$ \\
\hline 2 & $48.08(71)$ & $28.43(1)$ & $46.44(65)$ & $53.89(65)$ & $28.1(0)$ & $35.91(28)$ & $30.32(8)$ & $28.1(0)$ \\
\hline 3 & $51.21(82)$ & $28.6(2)$ & $53.49(90)$ & $66.8(90)$ & $28.1(0)$ & $39.44(40)$ & $31.61(12)$ & $28.1(0)$ \\
\hline 4 & $54.68(95)$ & $28.76(2)$ & $59.47(112)$ & $79.73(112)$ & $28.1(0)$ & $42.75(52)$ & $33.04(18)$ & $28.1(0)$ \\
\hline 5 & $58.52(108)$ & $28.92(3)$ & $64.59(130)$ & $92.66(130)$ & $28.1(0)$ & $45.84(63)$ & $34.62(23)$ & $28.1(0)$ \\
\hline 6 & $62.8(123)$ & $29.09(4)$ & $69.03(146)$ & $105.61(146)$ & $28.11(0)$ & $48.75(73)$ & $36.39(30)$ & $28.1(0)$ \\
\hline \multicolumn{9}{|c|}{ Global Emissions 2015} \\
\hline 0 & $19.08(0)$ & $19.08(0)$ & $19.08(0)$ & $19.08(0)$ & $19.08(0)$ & $19.08(0)$ & $19.08(0)$ & $19.08(0)$ \\
\hline 1 & $30.99(62)$ & $21.95(15)$ & $19.18(1)$ & 19.18 (1) & $19.08(0)$ & $22.84(20)$ & $19.08(0)$ & $19.08(0)$ \\
\hline 2 & $50.19(163)$ & $25.19(32)$ & $19.28(1)$ & $19.28(1)$ & $19.08(0)$ & $26.42(38)$ & $19.09(0)$ & $19.08(0)$ \\
\hline 3 & $78.2(310)$ & $28.83(51)$ & $19.38(2)$ & $19.38(2)$ & $19.08(0)$ & $29.84(56)$ & $19.1(0)$ & $19.08(0)$ \\
\hline 4 & $103.92(445)$ & $32.91(72)$ & $19.48(2)$ & $19.48(2)$ & $19.08(0)$ & $33.06(73)$ & $19.1(0)$ & $19.08(0)$ \\
\hline 5 & $65.19(242)$ & $37.36(96)$ & $19.59(3)$ & $19.59(3)$ & $19.07(0)$ & $36.08(89)$ & $19.1(0)$ & $19.08(0)$ \\
\hline 6 & $24.61(29)$ & $42.22(121)$ & $19.7(3)$ & $19.7(3)$ & $19.07(0)$ & 38.9 (104) & $19.11(0)$ & $19.08(0)$ \\
\hline
\end{tabular}

Notes: Figures for the social cost of carbon are 2005 dollars per ton of carbon; figures for global emissions are billions of tons of carbon per year. Numbers in parentheses refer to the percentage change relative to the mean value.

Source: Nordhaus (2008) and our own calculations.

suggests that growth in total factor productivity is the most important exogenous variable, with the other ones having a lower or negligible influence. This result is in agreement with intuition. In fact, growth in total factor productivity is the most important exogenous variable when economic growth is concerned. Because emissions are linked to the level of economic activity, growth in total factor productivity affects emissions as well. Fig. 2 shows that while $\delta_{l}$ for this exogenous variable is still the greatest by magnitude, other exogenous variables are not insignificant in influencing the distribution of future emissions. This provides a different message with respect to the results of Nordhaus ${ }^{(43)}$ reported in Table II.

We can go further. Besides a robust identification of the uncertainty drivers, the approach proposed here produces additional insights into model structure and direction of change.

To appraise interactions we apply the GUIHDMR Matlab code of Ziehn and Tomlin. ${ }^{(76)}$ On the basis of the discussion in Section 3.1, we find that the sum of the second-order sensitivity indices equals $\sum_{i, j=1}^{n} S_{i, j}=0.4233$ when the endogenous variable is the social cost of carbon in 2005 and $\sum_{i, j=1}^{n} S_{i, j}=0.6053$ when the endogenous variable is global emissions in 2105 . These values indicate that interaction effects are relevant and the model responds nonadditively to simultaneous variations in the exogenous variables. Examining these effects more closely one notes that the interaction between growth in total factor productivity and the price of the backstop technology (PBAKC) is the most influential on the social cost of carbon, while the interaction between the damage function exponential factor and climate sensitivity have the strongest effect on the level of global emissions in $2105 .^{8}$ As an illustration, Fig. 3 displays the HDMR of the most influential interactions for global emissions in 2105.

Fig. 3 shows the plot of the bivariate function $g_{A 2, T 2 X C 02}(A 2, T 2 X C 02)$ representing the interactions between the damage function exponential factor and climate sensitivity when the endogenous variable is global emissions. ${ }^{9}$ This second-order function is neither convex nor concave and nonmonotone. Also, note that the function is not strictly

${ }^{8}$ DICE-2007 explicitly includes a backstop technology, which is a technology that can replace all fossil fuels. It kicks in when the price of fossil fuels reaches a sufficiently high level. The backstop technology could be one that removes carbon from the atmosphere or an all-purpose environmentally benign zero-carbon energy technology.

${ }^{9}$ The representation in Fig. 3 is for illustrative purposes only. Of course, similar figures can be produced and analyzed for all combinations of the model exogenous variables. 


\section{Social Cost of Carbon in 2005}

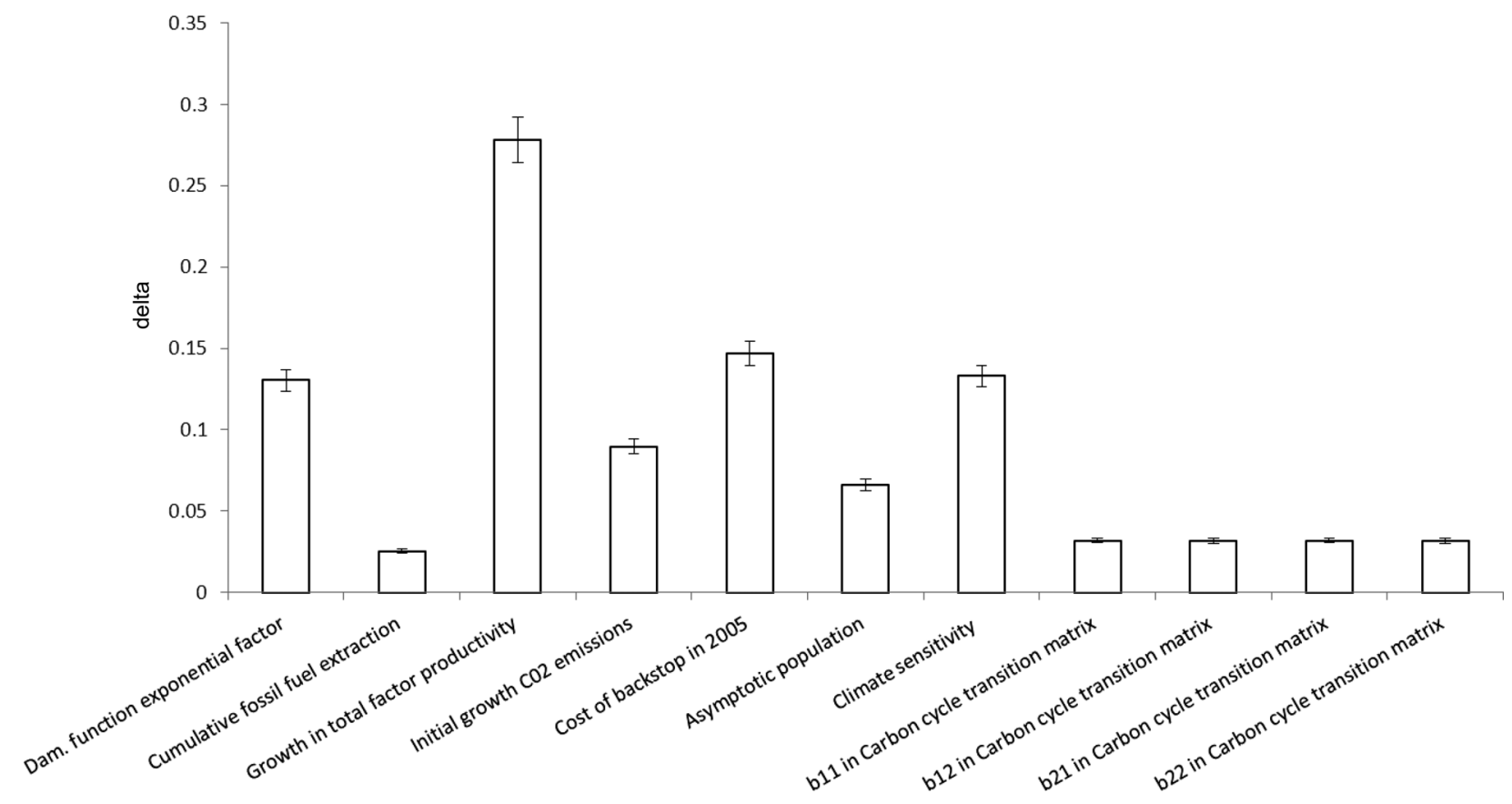

Fig. 1. $\delta_{i}(i=1,2, \ldots, 11)$ sensitivity indices when the endogenous variable is the social cost of carbon in 2005 . The boxplots represent the bootstrap confidence intervals on the estimates, obtained with 500 bootstrap replicates.

positive or negative across the entire uncertainty ranges for the interacting exogenous variables. When both exogenous variables are at the lower end of their uncertainty ranges, the interactive effect is a negative one, while at the upper end of the ranges the interactive effect has the opposite sign. For example, if we set climate sensitivity at a low value and we consider the effect on emissions of progressively higher values of the damage function exponential factor, the interaction effect would reduce the direct effect generated by the damage function exponential factor. However, if we set climate sensitivity at a high value, the opposite occurs. As a result, second-order effects can have either an amplifying or dampening impact on the first-order individual effects. The application of these methods thus provides a quantitative dimension to the statement that "an examination of all the uncertain exogenous variables taken together ... may produce unexpected results because of the interactions among the exogenous variables and the non-linearity in the DICE model." (43, p. 134)

By plotting the first-order terms in the HDMR decomposition of Equations (2) and (3), one gathers insights into the direction of change and monotonicity when exogenous variables vary individually.
Again for the sake of illustration, Fig. 4 shows the direction of change in the social cost of carbon due to an increase in climate sensitivity (T2XCO2) and in the level of global emissions due to an increase in the growth of total factor productivity. These are the two exogenous variables with the most significant HDMR effects.

The trend lines in Fig. 4 show that there is a monotonically increasing relationship between the value of climate sensitivity and the social cost of carbon; the same relationship characterizes growth in total factor productivity and total emissions at the end of the century. In fact, for both endogenous variables, the first-order functions $g_{i}\left(x_{i}\right)$ are monotonic. One can, of course, carry out a similar investigation to examine the behavior of these (and other) endogenous variables with respect to any of the remaining exogenous ones (this information is not reported here for brevity).

\subsection{Results When Uncertainty in All Exogenous Variables Is Considered}

We now focus on a novel methodological aspect that the approach proposed here allows. Namely, 


\section{Global Emissions in 2105}

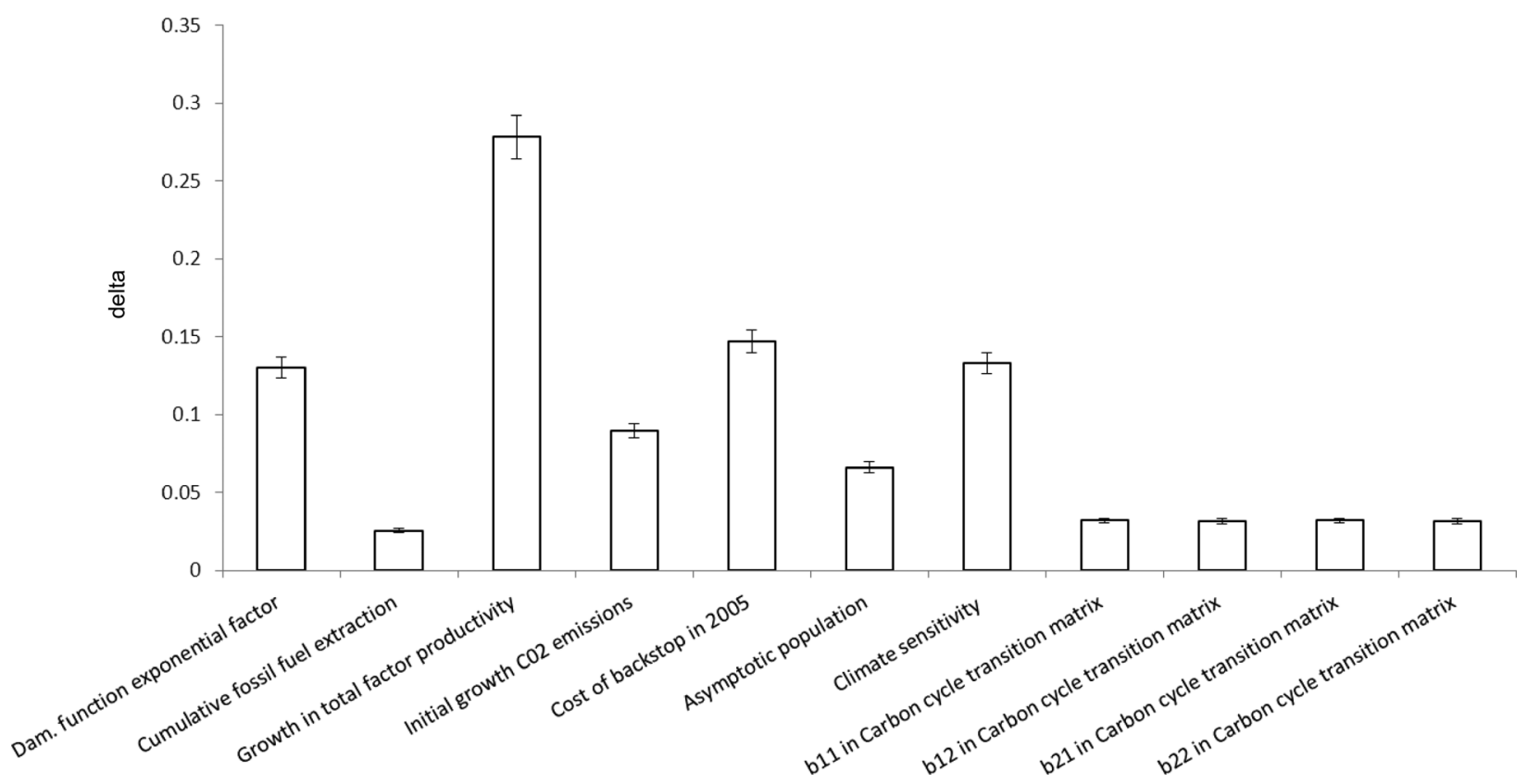

Fig. 2. $\delta_{i}(i=1,2, \ldots, 11)$ sensitivity indices when the endogenous variable is global emissions in 2105 . The boxplots represent the bootstrap confidence intervals on the estimates, obtained with 500 bootstrap replicates.

we can perform uncertainty and global sensitivity analysis of the DICE model when all 51 exogenous variables of DICE 2007 vary simultaneously. The analysis in Section 5.1 required $N$ model runs after propagation of uncertainty in eight exogenous variables. An appealing feature of our procedure is that the analysis still requires $N$ model runs with 51 varying exogenous variables. Relaxing the assumption on the number of uncertain exogenous variables, however, makes us deviate from the assumptions in Section 5.1. Eight of these variables have been studied and assigned distributions, while the remaining ones have not been considered for uncertainty propagation. Thus, to put all variables on the same ground, we have to take a step back and assume that we have little or no prior information on all exogenous variables. Thus, the spirit of the remainder of this section is that we are at an initial modeling phase, and we have not decided on which exogenous variables to collect further information.

To account for the lack of information one could use a noninformative Jeffreys's prior or adopt Laplace's ${ }^{(93)}$ principle of insufficient reason (see Gilboa and Marinacci ${ }^{(94)}$ for a theoretical explanation and Chun ${ }^{(95)}$ for practical implications of the choice of the prior). Adhering to Laplace's indiffer- ence principle, we report the results obtained assigning to all 51 exogenous variables a uniform distribution over a symmetric support around their base case value. Formally, the support of $X_{i}$ is assigned values equal to $\left[x_{i}^{0}-\lambda x_{i}^{0}, x_{i}^{0}+\lambda x_{i}^{0}\right]$, so that $\Omega_{X}=$ $\Omega_{X_{1}} \times \Omega_{X_{2}} \times \cdots \times \Omega_{X_{n}}$. Note that the resulting measure is Lebesgue. This measure is indeed the natural one in the HDMR expansion of the exogenousendogenous variable mapping. In the discussion below, we present findings obtained with $\lambda=0.1 .^{10} \mathrm{~A}$ Monte Carlo sample of size $N=10,000$ simulations is propagated using quasi-random sampling. By postprocessing the uncertainty analysis data set using the method of Plischke et al., ${ }^{(65)}$ we calculate the $\delta$ sensitivity measures.

Fig. 4 displays results when the endogenous variables of interest are the social cost of carbon in 2005 (top graph) and global emissions in 2105 (bottom graph).

\footnotetext{
${ }^{10}$ The choice of interval width is admittedly arbitrary, so that we repeated the analysis using intervals of $5 \%$ and $20 \%$, obtaining results consistent with the $10 \%$ case. In addition, following the suggestion of a referee, we also performed the analysis using Beta distributions over $5 \%, 10 \%$, and $20 \%$ ranges, obtaining consistent results.
} 


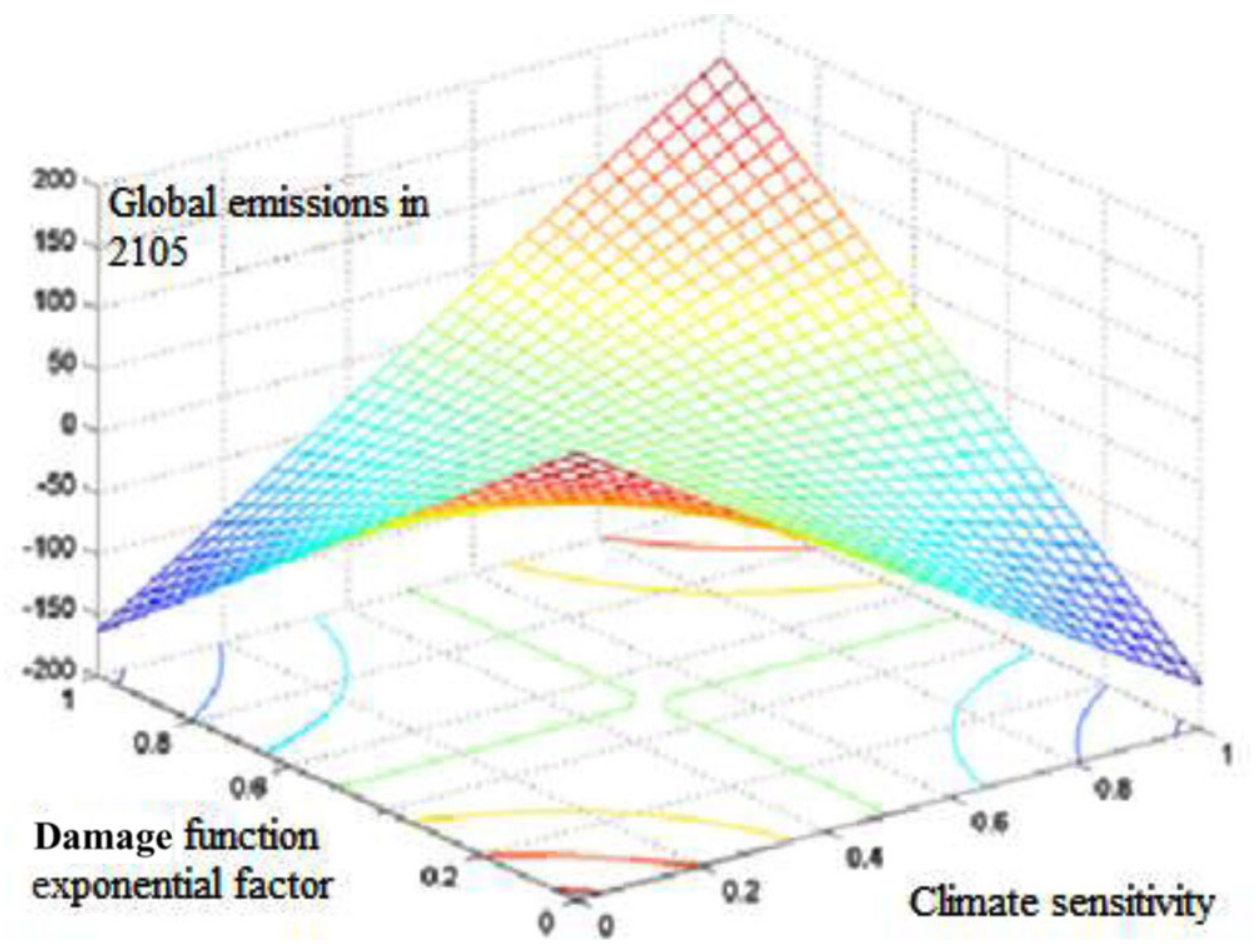

Fig. 3. Example of exogenous variable interaction for the case of global emissions in 2105 .

The exogenous variable "elasticity of capital in the Cobb-Douglas production function" (GAMA) has the strongest influence on the social cost of carbon in 2005 (top graph), followed by the damage function exponent (A3), the exponent in the damage function. Climate sensitivity, the elasticity of marginal utility of consumption (B.ELASMU), and the damage function exponential factor follow with roughly equal influence. For global emissions in 2105, the damage function exponent is of primary importance, followed by the emissions-GNP ratio (SIG0), the growth rate in total factor productivity, and the exponent in the cost control function.

Fig. 5 displays the results when the endogenous variables are atmospheric temperature in 2105 and at the optimal carbon tax in 2015.

The top graph in the figure shows that the exogenous variable initial productivity (A0) influences atmospheric temperature the most, followed closely by climate sensitivity, emissions-GNP ratio, elasticity of capital, and the control function exponent (EXPCOST2). The exponent in the damage function (A3) is the most influential exogenous variable for the optimal carbon tax (bottom graph), followed by elasticity of capital, initial productivity (A0), elasticity of marginal utility of consumption, and climate sen- sitivity. Finally, the elasticity of marginal utility of consumption is the single most influential exogenous variable for intergenerational utility, as seen in Fig. 6.

On the whole, Figs. 5-7 show that the exogenous variables elasticity of capital, initial productivity, and damage function exponent are systematically among the most influential across the five endogenous variables. The elasticity of marginal utility of consumption is extremely influential on intergenerational utility, but among the least influential on atmospheric temperature, in accordance with intuition.

These results allow us to investigate whether, when all 51 exogenous variables are allowed to vary, the eight exogenous variables considered in Section 5.1 are among the most important ones. Table III reports their ranking.

Table III shows that three out of eight exogenous variables are among the five most important ones: climate sensitivity (ranking second, third, and fifth in three out of four cases), growth in total factor productivity (ranking third in one case), and the damage function exponential factor (ranking fifth in one case). Four of them-initial sigma growth (GSIGMA), cost of backstop in 2005 (PBACK), b12, and cumulative fossil fuel extraction (FOSSLIM) are never among the eight most influential variables. 

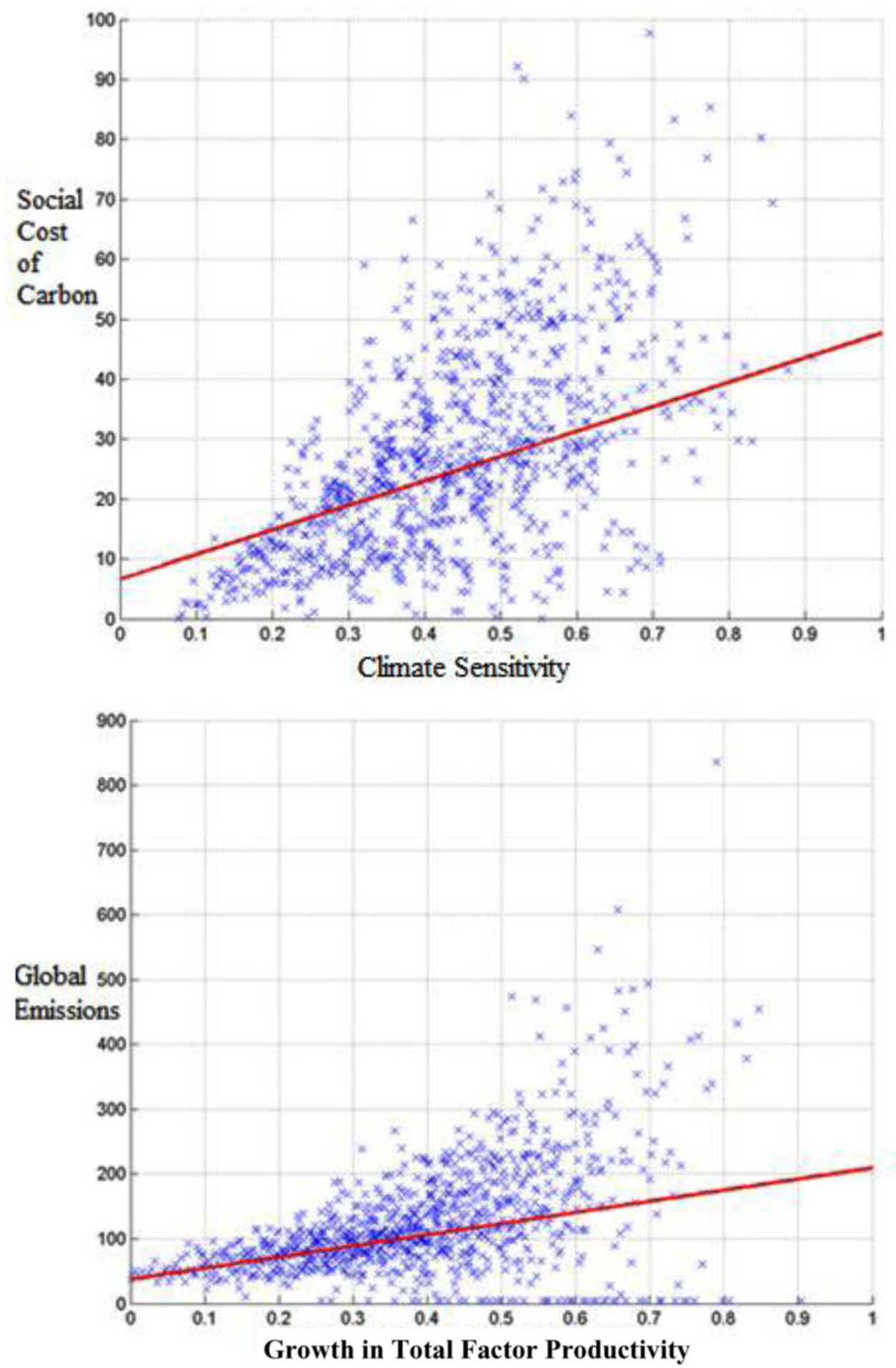

Fig. 4. Expected behavior of the social cost of carbon as a function of climate sensitivity (top) and of global emissions (bottom) as a function of the growth in total factor productivity. 


\section{Social Cost of Carbon in 2005}
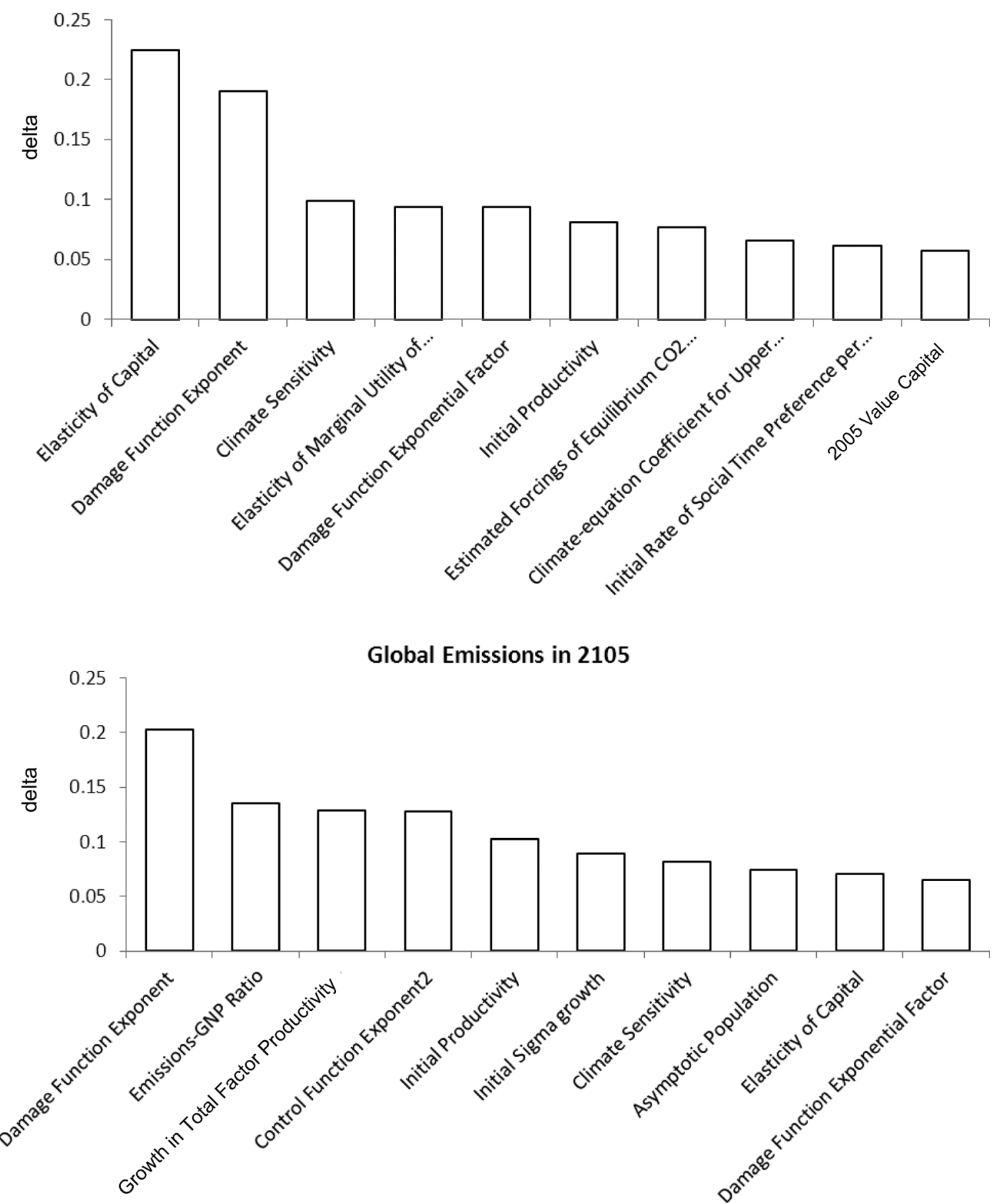

Fig. 5. $\delta_{l}$ sensitivity indices for the 10 most important exogenous variables when the endogenous variables are social cost of carbon in 2005 (top) and global emissions in 2105 (bottom). 


\section{Atmospheric Temperature in 2105}
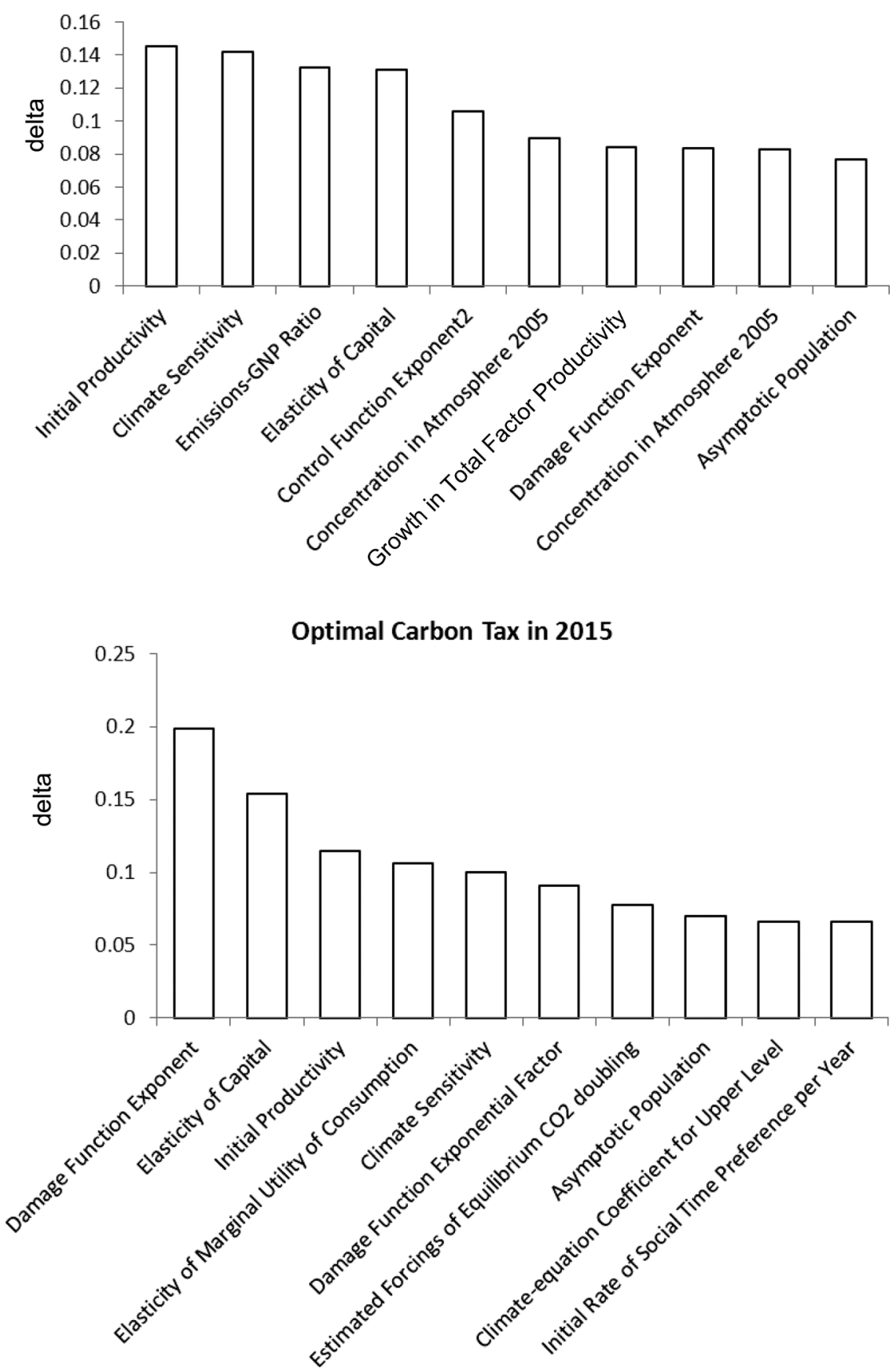

Fig. 6. $\delta_{l}$ sensitivity indices for the 10 most important exogenous variables when the endogenous variables are atmospheric temperature in 2105 (top) and carbon tax in 2015 (bottom).

Also, none among the eight exogenous variables of Section 5.1 ranks first with respect to any of the considered endogenous variables. These results have two relevant implications. The first concerns un- certainty management. Restricting attention to the eight variables of Section 5.1 in a hypothetical subsequent data collection would lead to overlooking the most important variable on each of the endogenous 


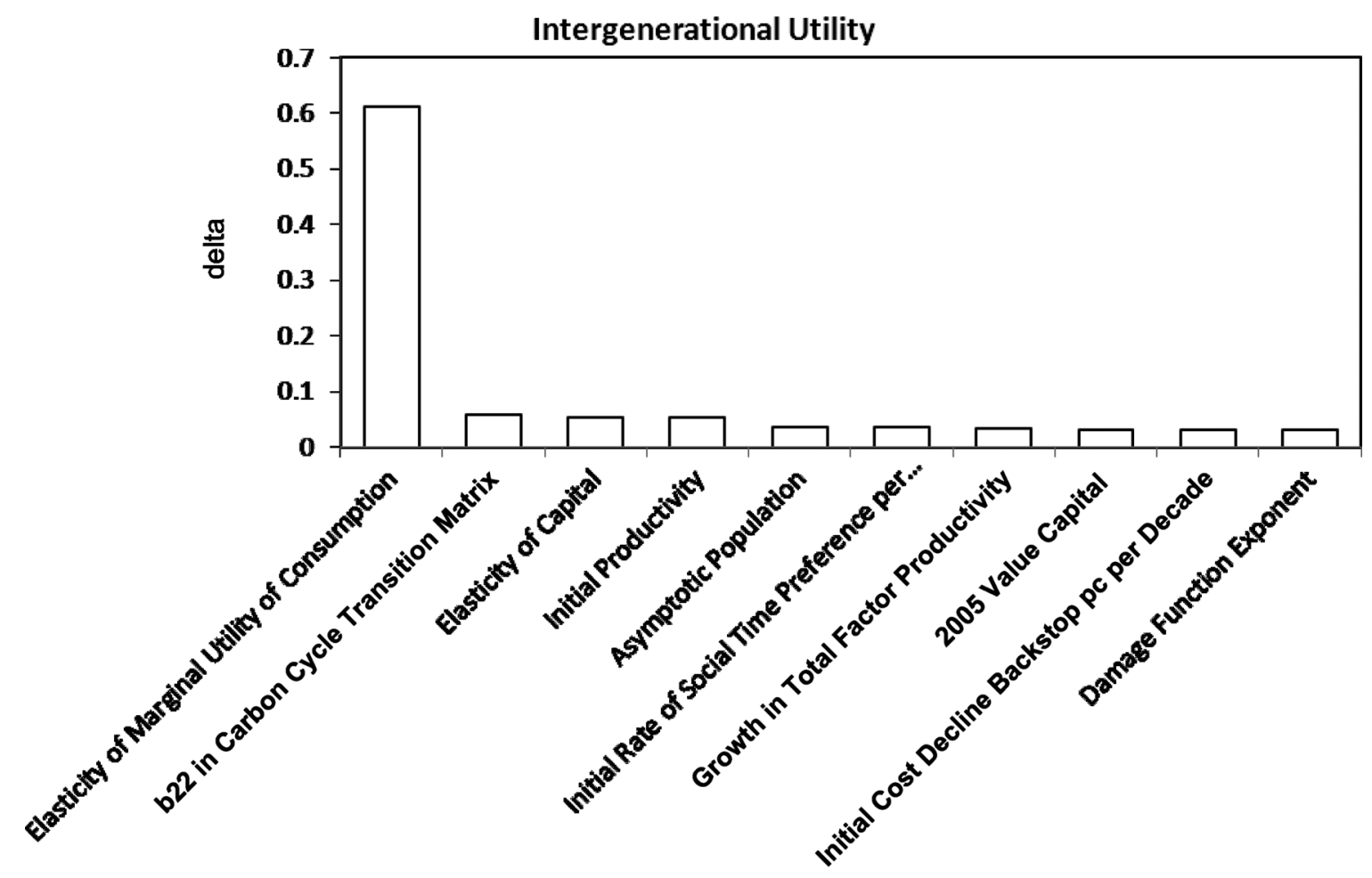

Fig. 7. $\delta_{l}$ for the 10 most important exogenous variables when the endogenous variable is intergenerational utility.

Table III. Nordhaus's (2008) Exogenous Variables SA Rank

\begin{tabular}{|c|c|c|c|c|}
\hline $\begin{array}{l}\text { Exogenous } \\
\text { Variable }\end{array}$ & $\begin{array}{c}\text { Social Cost } \\
\text { of Carbon } \\
\text { in } 2005\end{array}$ & $\begin{array}{l}\text { Global } \\
\text { Emissions } \\
\text { in } 2105\end{array}$ & $\begin{array}{l}\text { Atmospheric } \\
\text { Temperature } \\
\text { in } 2105\end{array}$ & $\begin{array}{c}\text { Carbon } \\
\text { Tax in } \\
2015\end{array}$ \\
\hline Growth in total factor productivity & 7 & 11 & 11 & 3 \\
\hline Initial sigma growth & 16 & 36 & 26 & 6 \\
\hline Climate sensitivity & 2 & 3 & 5 & 7 \\
\hline Damage function exponential factor & 22 & 5 & 6 & 10 \\
\hline Cost of backstop in 2005 & 17 & 32 & 29 & 12 \\
\hline Asymptotic population & 10 & 12 & 8 & 8 \\
\hline b12 in carbon cycle transition matrix & 12 & 13 & 12 & 21 \\
\hline Cumulative fossil fuel extraction & 42 & 26 & 30 & 34 \\
\hline
\end{tabular}

variables of interest. Thus, data or information collection could be suboptimal. The second is methodological, namely, these results raise the broad question about the method with which a set of exogenous variables can be preselected. This task can be performed either utilizing the methods proposed in this article or utilizing any of the available screening methods (see Campolongo et al. ${ }^{(69)}$ for an overview). However, in any case, the task needs to be carried out using a systematic approach in which first all model exogenous variables are varied and then the most im- portant ones are selected (this is in agreement with the observations in Saltelli and d'Hombres). ${ }^{(13)}$

We now devote attention to a more theoretical discussion concerning intergenerational utility, which is indeed the primary DICE endogenous variable. Fig. 6 showed that the exogenous variable driving variation in the intergenerational utility is, by far, the elasticity of the marginal utility of consumption (B.ELASMU). It is known that, in an intertemporal optimization setting like the one in DICE, the elasticity of marginal utility of consumption corresponds 
to the variable $\alpha$ in the Ramsey's equation:

$$
r=\rho+\alpha \cdot g,
$$

where $r$ is the social discount rate, $\rho$ is the rate of pure time preference, $g$ is the growth rate of consumption per capita, and $\alpha$ is the elasticity of marginal utility of consumption. The Stern Review assumes $\alpha=1$, which, together with $\rho=0.1$ and $g=1.4$, yields a discount rate of $1.4 \%$ a year. Nordhaus instead assumes $\rho=1.5$ and $\alpha=1.5$, obtaining a yearly $5 \%$ discount rate. $\alpha$ is also known as the coefficient of relative risk aversion because the DICE model uses a constant elasticity of substitution utility function:

$$
U\left[c(t), L(t)^{)}=L(t)\left(c(t)^{1-\alpha} /(1-\alpha),\right.\right.
$$

where $L(t)$ denotes labor force or population. $\alpha$ in Equation (18) determines the shape of the utility function and the relationship between consumption increases and utility or welfare. Sterner and Persson $^{(87)}$ succinctly explain the economic logic behind assumptions related to values for $\alpha$ : "the higher the value of $\alpha$, the less we care for a dollar more of consumption as we become richer. Since we expect that we will be richer in the future, when climate damages will be felt, a higher $\alpha$ also implies that damages will be valued lower. Thus, a higher value of $\alpha$ implies less greenhouse gas abatement today, unless for some reason we will be poorer rather than richer in the future. In this case, a higher $\alpha$ would give higher damage values, which would justify more abatement."(87, p. 66)

The findings displayed in Fig. 6 provide key support to the argument that numerical decisions affecting the exogenous variables of Ramsey's equation and implicitly the discount rate are of primary importance in IAMs. There is a long-standing debate about the appropriate choice of the discount rate in long-term policies, like the one associated with climate change, with notable contributions by Heal, ${ }^{(88)}$ Weitzman, ${ }^{(89)}$ and Newell and Pizer. ${ }^{(90)}$ The debate was reignited after the publication of the Stern Review, ${ }^{(91)}$ as many critics argue that most of Stern's results depend on the choice of a very low (possibly implausible) discount rate. ${ }^{(24,25,29,51)}$ Indeed, using alternative combinations of $\alpha$ and $\rho$, Nordhaus ${ }^{(92)}$ derives alternative real interest rates and values of the social cost of carbon. In particular, the Stern Review $\rho=0.1$ and Nordhaus's $5 \%$ real interest rate imply $\alpha=2$, so that DICE's social cost of carbon increases but to a value that is only about one-tenth of the one implied by the Stern Review.
Our analysis confirms not only that this exogenous variable is key for results, but it also allows us to understand how important it is. In this respect, we also studied how this exogenous variable interacts with other exogenous variables in the model. The strongest interaction is with the production function elasticity of capital, which is one of the most relevant exogenous variables of the DICE model. The production function elasticity of capital directly affects the marginal productivity of capital: a high value of it implies that investing today (thereby postponing consumption) will pay back in the future with high returns on income. It then comes with little surprise that interactions between the elasticity of capital and the elasticity of marginal utility of consumption are important, as both exogenous variables directly influence the intertemporal allocation of resources.

Economists and policymakers are not only interested in drivers of intergenerational utility, which in itself is an abstract concept, but they focus also on more pragmatic variables that are of relevancesuch as the level of total emissions at the end of the century — and actionable — such as magnitudes of carbon taxes. As a final step, we consider the full rankings induced by $\delta_{i}$ on all endogenous variables. They are reported in Table IV.

A qualitative inspection of the ranking in the table has been discussed earlier. The inspection can be made quantitative utilizing the standard approach based on Spearman rank and Savage score correlation coefficients (see Iman and Conover ${ }^{(96)}$ ). We denote them by $\rho_{R}\left(y_{i}, y_{j}\right)$ and $\rho_{S}\left(y_{i}, y_{j}\right)$, respectively. The reason for computing both indexes is that a comparison of these values is informative about the agreement at the level of the most important exogenous variables. In particular, if $\rho_{R}\left(y_{i}, y_{j}\right)<\rho_{S}\left(y_{i}, y_{j}\right)$, then ranking agreement among the top ranked exogenous variables is higher than average, if $\rho_{R}\left(y_{i}, y_{j}\right)>$ $\rho_{S}\left(y_{i}, y_{j}\right)$, the converse is true.

For the rankings in Table IV, the numerical values of $\rho_{R}\left(y_{i}, y_{j}\right)$ and $\rho_{S}\left(y_{i}, y_{j}\right)$ are reported in Table $\mathrm{V}$.

To illustrate, consider as an example the entry at the intersection of carbon tax (row) and social cost of carbon (column). The corresponding coefficients are equal to $\rho_{R}=0.958$ and $\rho_{S}=0.951$, respectively. Such values indicate a strong ranking agreement. Thus, the exogenous variables that are influential on the social cost of carbon are also influential for the carbon tax. Consider now the entry corresponding to global emissions (row) and social cost of carbon. We have $\rho_{R}=0.657$ and $\rho_{S}=0.599$. These values indicate that the ranking agreement is 
Table IV. $\delta$ Ranking

\begin{tabular}{|c|c|c|c|c|c|}
\hline $\begin{array}{l}\text { Exogenous } \\
\text { Variable }\end{array}$ & $\begin{array}{l}\text { Social Cost of } \\
\text { Carbon in } 2005\end{array}$ & $\begin{array}{l}\text { Global Emissions } \\
\text { in } 2105\end{array}$ & $\begin{array}{c}\text { Atmospheric } \\
\text { Temperature in } 2105\end{array}$ & $\begin{array}{l}\text { Carbon Tax } \\
\text { in } 2015\end{array}$ & $\begin{array}{c}\text { Intergenerational } \\
\text { Utility }\end{array}$ \\
\hline A 0 & 6 & 5 & 1 & 3 & 4 \\
\hline A1 & 43 & 43 & 43 & 43 & 43 \\
\hline $\mathrm{A} 2$ & 5 & 10 & 22 & 6 & 42 \\
\hline A3 & 2 & 1 & 8 & 1 & 10 \\
\hline BACKRAT & 20 & 24 & 34 & 27 & 12 \\
\hline B'ELASMU & 4 & 11 & 19 & 4 & 1 \\
\hline B'PRSTP & 9 & 15 & 29 & 10 & 6 \\
\hline $\mathrm{C} 1$ & 8 & 14 & 18 & 9 & 23 \\
\hline $\mathrm{C} 3$ & 27 & 19 & 23 & 20 & 27 \\
\hline $\mathrm{C} 4$ & 17 & 28 & 30 & 18 & 25 \\
\hline DELA & 39 & 31 & 37 & 40 & 22 \\
\hline DK & 33 & 38 & 24 & 33 & 31 \\
\hline DPARTFRACT & 43 & 43 & 43 & 43 & 43 \\
\hline DSIG & 37 & 26 & 40 & 31 & 32 \\
\hline DSIG2 & 43 & 43 & 43 & 43 & 43 \\
\hline ELAND0 & 31 & 42 & 39 & 42 & 15 \\
\hline EXPCOST2 & 21 & 4 & 5 & 19 & 21 \\
\hline FCO22X & 7 & 13 & 15 & 7 & 17 \\
\hline FEX0 & 38 & 35 & 41 & 35 & 41 \\
\hline FEX1 & 30 & 39 & 33 & 41 & 24 \\
\hline FOSSLIM & 26 & 34 & 42 & 30 & 13 \\
\hline GA0 & 11 & 3 & 7 & 11 & 7 \\
\hline GAMA & 1 & 9 & 4 & 2 & 3 \\
\hline GBACK & 29 & 25 & 38 & 25 & 9 \\
\hline GPOP0 & 25 & 32 & 28 & 24 & 39 \\
\hline GSIGMA & 36 & 6 & 16 & 26 & 38 \\
\hline K0 & 10 & 40 & 31 & 16 & 8 \\
\hline LIMMIU & 43 & 43 & 43 & 43 & 43 \\
\hline MAT2000 & 19 & 29 & 9 & 15 & 40 \\
\hline ML2000 & 35 & 41 & 21 & 39 & 30 \\
\hline MU2000 & 28 & 27 & 6 & 23 & 29 \\
\hline PARTFRACT1 & 43 & 43 & 43 & 43 & 43 \\
\hline PARTFRACT2 & 43 & 43 & 43 & 43 & 43 \\
\hline PARTFRACT21 & 43 & 43 & 43 & 43 & 43 \\
\hline PBACK & 32 & 12 & 17 & 29 & 16 \\
\hline POP0 & 23 & 30 & 20 & 28 & 11 \\
\hline POPASYM & 12 & 8 & 10 & 8 & 5 \\
\hline Q0 & 24 & 36 & 38 & 32 & 26 \\
\hline SIG0 & 22 & 2 & 3 & 21 & 28 \\
\hline $\mathrm{T} 2 \mathrm{XCO} 2$ & 3 & 7 & 2 & 5 & 14 \\
\hline TATM0 & 34 & 33 & 35 & 34 & 36 \\
\hline TOCEANO & 18 & 37 & 32 & 22 & 37 \\
\hline b11 & 13 & 21 & 12 & 12 & 18 \\
\hline b12 & 13 & 21 & 12 & 12 & 18 \\
\hline b21 & 13 & 21 & 12 & 12 & 18 \\
\hline b22 & 16 & 20 & 11 & 17 & 2 \\
\hline b23 & 40 & 16 & 26 & 36 & 34 \\
\hline b32 & 40 & 16 & 26 & 36 & 34 \\
\hline b33 & 42 & 18 & 25 & 38 & 33 \\
\hline scale1 & 43 & 43 & 43 & 43 & 43 \\
\hline scale2 & 43 & 43 & 43 & 43 & 43 \\
\hline
\end{tabular}


Table V. Spearman and Savage Score Correlation Coefficients

\begin{tabular}{|c|c|c|c|c|c|}
\hline & $\begin{array}{l}\text { Social Cost of } \\
\text { Carbon in } 2005\end{array}$ & $\begin{array}{l}\text { Global Emissions } \\
\text { in } 2105\end{array}$ & $\begin{array}{c}\text { Atmospheric } \\
\text { Temperature in } 2105\end{array}$ & $\begin{array}{l}\text { Carbon Tax } \\
\text { in } 2015\end{array}$ & $\begin{array}{c}\text { Intergenerational } \\
\text { Utility }\end{array}$ \\
\hline Social cost of carbon & 1 & & & & \\
\hline Global emissions & $0.657 \mid 0.599$ & 1 & & & \\
\hline Atmospheric temperature & $0.709 \mid 0.613$ & $0.816 \mid 0.718$ & 1 & & \\
\hline Carbon tax & $0.958 \mid 0.951$ & $0.774 \mid 0.717$ & $0.789 \mid 0.669$ & 1 & \\
\hline Intergenerational utility & $0.731 \mid 0.645$ & $0.554 \mid 0.388$ & $0.545 \mid 0.430$ & $0.669 \mid 0.622$ & 1 \\
\hline
\end{tabular}

Note: In each entry, the two coefficients $\rho_{R}\left(y_{i}, y_{j}\right)$ and $\rho_{S}\left(y_{i}, y_{j}\right)$ are separated by a vertical bar.

not strong. Also, the fact that $\rho_{R}>\rho_{S}$ in this case indicates that the disagreement is higher (on average) at the level of key drivers than at the level of the noninfluential factors.

Table $\mathrm{V}$ indicates a systematically low value of $\rho_{R}$ and $\rho_{S}$ when intergenerational utility is considered. Conversely, the ranking agreement among the other exogenous variables is higher. In particular:

- The optimal carbon tax coincides with the social cost of carbon discounted at 2015: this explains the very high correlation with the same variable discounted at 2005;

- The social cost of carbon provides a monetary measure of the marginal impact of a ton of carbon on discounted utility: this explains the high rank correlation between social cost and utility; and

- Temperature depends on radiative forcing, which depends on GHGs concentration, which depends on emissions: this explains the strong rank correlation between temperature and emissions.

In general, exogenous variables could be split into a group of speculative exogenous variables whose value is not empirically known and is calculated through projections or specific assumptions, and a group of exogenous variables that are econometric in nature and depend on statistical analysis. It is common to take the econometric group of exogenous variables as given and instead focus on the speculative exogenous variables when performing sensitivity or scenario analysis. Our results show that uncertainty in both types of exogenous variables is influential ex ante. Thus, the practical recommendation that emerges is that global SA should be used to quantify the relevance of all exogenous variables, without excluding some from the quantitative analysis. One is then ensured that further analysis conducted on the resulting key drivers is robust to poten- tial criticism on the way sensitivity analysis has been used.

Finally, we also postprocessed the data to obtain information on the direction of change and interactions when all 51 exogenous variables vary. Results are similar to those reported in Figs. 2 and 3 where first-order effects are monotonic and second-order interaction effects are significant and nonmonotonic. To conserve on space the results are not reported here.

\section{CONCLUSIONS}

This article has demonstrated the usefulness of global sensitivity analysis methods in the area of integrated assessment modeling for climate change economics. It has shown that, at the same computational cost of a standard uncertainty analysis, we can obtain robust insights into direction of change, model structure (interactions), and key uncertainty drivers. These insights provide analysts with a deeper understanding of a model behavior and allow them to robustly identify the exogenous variables on which to focus additional data and information collection.

A further advantage of the methods proposed and described in this article is that significant interactions can be identified explicitly, rather than simply acknowledged or speculated upon, and the direction of the interaction effect can be observed.

We have discussed both numerical and methodological aspects of the approach using DICE, one of the most popular models for climate change policy analysis. The results show that the elasticity of the marginal utility of consumption, which influences the discount rate applied, is by far the most influential exogenous variable in affecting the dependent variable in the objective function of the model, intergenerational utility. The key uncertainty drivers have been also identified with respect to more pragmatic policy-relevant endogenous variables, including social cost of carbon and carbon tax on one 
hand, and emissions and temperature on the other. Differences in ranking of the exogenous variables with respect to the endogenous variables have been analyzed.

The results of this article highlight the merits of performing global sensitivity analysis alongside other types of scenario analysis. The most highly visible recent analysis of IAMs in the climate change literature revolved around what type of scenario should be considered as a most reasonable informer for policy. The authors of the Stern Review claim that a scenario with low discount rates and strong intergenerational equity is the correct basis, while others avoid the "normative" discussions on discount rates, using instead observable market rates of return and arriving at much different conclusions and policy recommendations. While this highlights the usefulness of varied modeling strategies for different policy or scientific questions, our exercise has shown the benefits of using global sensitivity analysis methods since the two approaches are not interchangeable and important information can be obtained from both. Finally, global sensitivity analysis along the lines presented here could be fruitfully conducted on other classes of models routinely used in climate change policy analysis, from computable general equilibrium models for impact assessment to energy system technoeconomic models.

\section{ACKNOWLEDGMENTS}

The authors wish to thank the Editors Prof. Tony Cox and Michael Greenberg, the Area Editor, Prof. Wayne Landis, and the anonymous referees for the very perceptive suggestions that have greatly helped improve the article. The authors are grateful to the participants of the IEFE BocconiFondazione Eni Enrico Mattei joint seminar series on Environment and Climate Change and especially to Valentina Bosetti for useful comments. The authors also thank Klaus Keller for very useful discussions. The authors also thank the reviewers of the 6th International Congress on Environmental Modelling and Software (iEMSs) 1-5 July, 2012, Leipzig (Germany), for perceptive comments and observations.

\section{REFERENCES}

1. Hammitt JK, Lempert RJ, Schlesinger ME. A sequentialdecision strategy for abating climate change. Nature, 1992; 357:315-318.
2. Baker E. Optimal policy under uncertainty and learning about climate change: A stochastic dominance approach. Journal of Public Economic Theory, 2009; 11:721-747.

3. Hall JW, Lempert RJ, Keller K, Hackbarth A, Mijere C, McInerney DJ. Robust climate policies under uncertainty: A comparison of robust decision making and info-gap methods. Risk Analysis, 2012; 32:1657-1672.

4. Pindyck RS. Uncertain outcomes and climate change policy. Journal of Environmental Economics and Management, 2012; 63:289-303.

5. Lorenzoni I, Pidgeon NF, O'Connor RE. Dangerous climate change: The role for risk research. Risk Analysis, 2005; 25:1387-1398.

6. Aven T. On the need for restricting the probabilistic analysis in risk assessments to variability. Risk Analysis, 2010; 30:354360.

7. Aven T. On different types of uncertainties in the context of the precautionary principle. Risk Analysis, 2011; 31:15151525 .

8. Aven T. Foundational issues in risk assessment, and risk management. Risk Analysis, 2012; 32:1647-1656.

9. Pidgeon N. Climate change risk perception and communication: Addressing a critical moment? Risk Analysis, 2012; 32:952-955.

10. Tol RSJ. Is the uncertainty about climate change too large for expected cost-benefit analysis? Climatic Change, 2003; 56:265289.

11. Weitzman ML. On modeling and interpreting the economics of catastrophic climate change. Review of Economics and Statistics, 2009; 91:1-19.

12. Risbey J, Van Der Sluijs P, Kloprogge J, Ravetz S, Funtowicz J, Quintana SC. Application of a checklist for quality assistance in environmental modelling to an energy model. Environmental Modeling and Assessment, 2005; 10:63-79.

13. Saltelli A, d'Hombres B. Sensitivity analysis didn't help. A practitioner's critique of the Stern Review. Global Environmental Change, 2010; 20:298-302.

14. Oppenheimer M, O' Neill BC, Webster M, Agrawala S. Climate change: The limits of consensus. Science, 2007; 317:15051506.

15. Swart R, Bernstein L, Ha-Duong M, Petersen A. Agreeing to disagree: Uncertainty management in assessing climate change, impacts and responses by the IPCC. Climatic Change, 2009; 92:1-29.

16. Webster M. Uncertainty and the IPCC: A comment. Climatic Change, 2009; 92:37-40.

17. U.S. EPA. Guidance on the Development, Evaluation, and Application of Environmental Models (EPA/100/K-09/003), 2009.

18. Iman RL, Johnson ME, Watson CC, Jr. Sensitivity analysis for computer model projections of hurricane losses. Risk Analysis, 2005; 25:1277-1297.

19. Iman RL, Johnson ME, Watson CC, Jr. Uncertainty analysis for computer model projections of hurricane losses. Risk Analysis, 2005; 25:1299-1312.

20. Rabitz H. System analysis at the molecular scale. Science, 1989; 246:221-226.

21. Saltelli A, Annoni P. How to avoid a perfunctory sensitivity analysis. Environmental Modelling \& Software, 2010; 25:1508-1517.

22. Dietz S, Anderson D, Stern N, Taylor C, Zenghelis D. Right for the right reasons. World Economics, 2007; 8:229-258.

23. Dietz S, Hope C, Stern N, Zenghelis D. Reflections on the Stern Review (1). A robust case for strong action to reduce the risks of climate change. World Economics, 2007; 8:121168.

24. Nordhaus WD. Critical assumptions in the Stern Review on climate change. Science, 2007; 317:201-202. 
25. Nordhaus WD. A review of the "Stern Review on the Economics of Climate Change." Journal of Economic Literature, 2007; 45:686-702.

26. Stern N, Taylor C. Climate change: Risk, ethics, and the Stern Review. Science, 2007; 317:203-204.

27. Tol RSJ, Yohe GW. A review of the Stern Review. World Economics, 2006; 7:233-250.

28. Tol RSJ, Yohe GW. A stern reply to the reply to the review of the Stern Review. World Economics, 2007; 2:153-159.

29. Weitzman ML. A review of the Stern Review on the economics of climate change. Journal of Economic Literature, 2007; 45:703-724.

30. Rabitz H, Alis ÖF. General foundations of high-dimensional model representations. Journal of Mathematical Chemistry, 1999; 25:197-233.

31. Most D, Keles D. A survey of stochastic modeling approaches for liberalised electricity markets. European Journal of Operational Research, 2010; 207:543-556.

32. Jannsen MA. Optimization of a non-linear dynamical system for global climate change. European Journal of Operational Research, 1997; 99:322-335.

33. Forgó F, Fülöp J, Prill M. Game theoretic models for climate change negotiations. European Journal of Operational Research, 2005; 160:252-267.

34. Fishbone LG, Abilock H. MARKAL, a linear-programming model for energy systems analysis: Technical description of the BNL version. International Journal of Energy Research, $1981 ; 5: 353-375$.

35. Kanudia A, Loulou R. Robust responses to climate change via stochastic MARKAL: The case of Québec. European Journal of Operational Research, 1998; 106:15-30.

36. Baker E, Solak S. Climate change and optimal energy technology R\&D policy original research. European Journal of Operational Research, 2011; 213:442-454.

37. Golub A, Narita D, Schmidt MG. Uncertainty in integrated assessment models of climate change: Alternative analytical approaches. FEEM working paper no. 2.2011, 2011.

38. Millner A, Dietz S, Heal G. Ambiguity and climate policy. NBER working paper no. 16050, 2010.

39. Lemoine DM, Traeger CP. Tipping points and ambiguity in the economics of climate change. CUDARE working paper no. 1111R, 2011.

40. Iverson T, Perrings C. Precaution and proportionality in the management of global environmental change. Global Environmental Change, 2012; 22(1):161-177.

41. Tol RSJ. The social cost of carbon: Trends, outliers and catastrophes. Economics: The Open-Access. Open-Assessment EJournal, 2008; 2:2008-2025.

42. Nordhaus WD. Managing the Global Commons: The Economics of Climate Change. Cambridge: MIT Press, 1994.

43. Nordhaus WD. A Question of Balance-Weighing the Options on Global Warming Policies. New Haven: Yale University Press, 2008.

44. Hope CW. The marginal impact of $\mathrm{CO}_{2}$ from PAGE2002: An integrated assessment model incorporating the IPCC's five reasons for concern. Integrated Assessment Journal, 2006; 6:19-56.

45. Dietz S. High impact, low probability? An empirical analysis of risk in the economics of climate change. Climatic Change, 2011; 108:519-541.

46. Nordhaus WD, Popp D. What is the value of scientific knowledge? An application. Energy Journal, 1997; 18: $1-45$.

47. Popp D. ENTICE: Endogenous technological change in the DICE model of global warming. Journal of Environmental Economics and Management, 2004; 48:742-768.

48. Dietz S, Asheim GB. Climate policy and sustainable discounted utilitarianism. Journal of Environmental Economics and Management, 2012; 63:321-335.
49. van Vuuren DP, de Vries B, Beusen A, Heuberger PSC. Conditional probabilistic estimates of 21st century greenhouse gas emissions based on the storylines of the IPCC-SRES scenarios. Global Environmental Change, 2008; 18:635-654.

50. Hof A, Denelzen M, Van Vuuren D. Analysing the costs and benefits of climate policy: Value judgments and scientific uncertainties. Global Environmental Change, 2008; 18:412424.

51. Anthoff D, Tol RSJ. The uncertainty about the social cost of carbon: A decomposition analysis using FUND. Economic and Social Research Institute Technical Report No. WP404, 2011.

52. Campolongo F, Saltelli A. Sensitivity analysis of an environmental model: An application of different analysis methods. Reliability Engineering and System Safety, 1997; 57:49-69.

53. Sobol' IM. Sensitivity analysis for nonlinear mathematical models. Mathematical Modeling \& Computational Experiment (English translation), 1993; 1:407-414.

54. Saltelli A, Ratto M, Andres T, Campolongo F, Cariboni J, Gatelli D, Saisana M, Tarantola S. Global Sensitivity Analysis-The Primer. Chichester: John Wiley \& Sons, 2008.

55. Helton JC, Davis FJ. Illustration of sampling-based methods for uncertainty and sensitivity analysis. Risk Analysis, 2002; 22:591-622.

56. Saltelli A, Tarantola S. On the relative importance of input factors in mathematical models: Safety assessment for nuclear waste disposal. Journal of the American Statistical Association, 2002; 97:702-709.

57. Saltelli A. Sensitivity analysis for importance assessment. Risk Analysis, 2002; 22:579-587.

58. Borgonovo E. Sensitivity analysis with finite changes: An application to modified EOQ models. European Journal of Operational Research, 2010; 200:127-138.

59. Efron B, Stein C. The jackknife estimate of variance. Annals of Statistics, 1981; 9:586-596.

60. Iman R, Hora S. A robust measure of uncertainty importance for use in fault tree system analysis. Risk Analysis, 1990; 10:401-406

61. Samuelson P. Foundations of Economic Analysis. Cambridge: Harvard University Press, 1947.

62. Borgonovo E. Measuring uncertainty importance: Investigation and comparison of alternative approaches. Risk Analysis, 2006; 26:1349-1362.

63. Borgonovo E. A new uncertainty importance measure. Reliability Engineering and System Safety, 2007; 92:771-784.

64. Borgonovo E, Castaings W, Tarantola S. Moment independent importance measures: New results and analytical test cases. Risk Analysis, 2011; 31:404-428.

65. Plischke E, Borgonovo E, Smith CL. Global sensitivity measures from given data. European Journal of Operational Research, 2013; 226(3):536-550.

66. Baucells M, Borgonovo E. Invariant probabilistic sensitivity analysis. Management Science, doi: mnsc.2013.1719.

67. Saltelli A. Making best use of model evaluations to compute sensitivity indices. Computer Physics Communications, 2012; 145:280-294.

68. Saltelli A, Annoni P, Azzini I, Campolongo F, Ratto M, Tarantola S. Variance-based sensitivity analysis of endogenous variable. Design and estimator for the total sensitivity index. Computer Physics Communications, 2010; 181:259-270.

69. Campolongo F, Saltelli A, Cariboni J. From screening to quantitative sensitivity analysis. A unified approach. Computer Physics Communications, 2011; 182:978-988.

70. Castaings W, Borgonovo E, Morris MD, Tarantola S. Sampling strategies in density-based sensitivity analysis. Environmental Modelling \& Software, 2012; 38:13-26.

71. Kleijnen JPC. Kriging metamodeling in simulation: A review. European Journal of Operational Research, 2009; 192(3):707716. 
72. Oakley J, O'Hagan A. Probabilistic sensitivity analysis of complex models: A Bayesian approach. Journal of the Royal Statistical Society Series B, 2004; 66:751-769.

73. Sudret B. Global sensitivity analysis using polynomial chaos expansions. Reliability Engineering \& System Safety, 2008; 93:964-979.

74. Blatman G, Sudret B. Efficient computation of global sensitivity indices using sparse polynomial chaos expansions. Reliability Engineering \& System Safety, 2010; 95:1216-1229.

75. Ratto M, Pagano A. Using recursive algorithms for the efficient identification of smoothing spline ANOVA models. Advances in Statistical Analysis, 2010; 94:367-388.

76. Ziehn T, Tomlin AS. GUI-HDMR-A software tool for global sensitivity analysis of complex models. Environmental Modelling \& Software, 2009; 24:775-785.

77. Keller K, Bolker BM, Bradford DF. Uncertain climate thresholds and optimal economic growth. Journal of Environmental Economics and Management, 2004; 48:723-741.

78. McInerney D, Keller K. Economically optimal risk reduction strategies in the face of uncertain climate threshold responses. Climatic Change, 2008; 91:29-41.

79. McInerney D, Lempert R, Keller K. What are robust strategies in the face of uncertainty? Climatic Change, 2011; 91:2941.

80. Nordhaus WD, Yang Z. A regional dynamic general equilibrium model of alternative climate-change strategies. American Economic Review, 1996; 86:741-765.

81. Eyckmans J, Tulkens H. Simulating coalitionally stable burden sharing agreements for the climate change problem. Resource and Energy Economics, 2003; 25:299-327.

82. Buonanno P, Carraro C, Galeotti M. Endogenous induced technical change and the costs of Kyoto. Resource and Energy Economics, 2003; 25:11-34.

83. Castelnuovo E, Galeotti M, Gambarelli G, Vergalli S. Learning by doing vs. learning by researching in a model for climate policy analysis. Ecological Economics, 2005; 54:261-276.
84. Bosetti V, Galeotti M, Lanza A. How consistent are alternative short-term climate policies with long-term goals? Climate Policy, 2006; 6:295-312.

85. de Bruin K, Dellink R, Tol RSJ. AD-DICE: An implementation of adaptation in the DICE model. University of Hamburg et Centre for Marine and Atmospheric Science working paper no. FNU-126, 2007.

86. Bosello F, Chen C. Adapting and mitigating to climate change: Balancing the choice under uncertainty, Fondazione Eni Enrico Mattei working paper no. 2010.159, 2010.

87. Sterner T, Persson UM. An even sterner review: Introducing relative prices into the discounting debate. Review of Environmental Economics and Policy, 2008; 2:61-76.

88. Heal G. Discounting and climate change. Climatic Change, 1997; 37:335-343

89. Weitzman ML. Why the far-distant future should be discounted at its lowest possible rate? Journal of Environmental Economics and Management, 1998; 36:201-208.

90. Newell RG, Pizer WA. Discounting the distant future: How much do uncertain rates increase valuations? Journal of Environmental Economics and Management, 2003; 46:52-71.

91. Stern N. The Economics of Climate Change: The Stern Review. Cambridge: Cambridge University Press, 2007.

92. Nordhaus WD. Integrated Economic and Climate Modeling. Cowles Foundation Discussion Paper No. 1839, 2011.

93. Laplace PS. Essai Philosophique sur les Probabilités. Paris: Gauthier-Villars (English edition: A Philosophical Essay on Probabilities. New York: Dover, 1951), 1814.

94. Gilboa I, Marinacci M. Ambiguity and the Bayesian paradigm. In Acemoglu D, Arellano M, Dekel E (eds). Advances in Economics and Econometrics: Theory and Applications. Cambridge: Cambridge University Press, 2013.

95. Chun Y. Bayesian analysis of the sequential inspection plan via the Gibbs sampler. Operations Research, 2008; 56:235-246.

96. Iman RL, Conover WJ. A measure of top-down correlation. Technometrics, 1987; 29:351-357. 